\title{
Mechanistic Insights into the Production of Methyl Lactate by Catalytic Conversion of Carbohydrates on Mesoporous Zr-SBA-15
}

\author{
Lisha Yang ${ }^{1}$, Xiaokun Yang ${ }^{1}$, Elli Tian ${ }^{2}$, Vivek Vattipalli ${ }^{3}$, Wei Fan ${ }^{3}$, and Hongfei Lin ${ }^{1 *}$ \\ ${ }^{1}$ Department of Chemical and Materials Engineering, \\ University of Nevada, Reno \\ 1664 N. Virginia St., Reno, NV 89557, USA. \\ Fax: (+1) 775-327-5059; \\ ${ }^{2}$ Department of Biomedical Engineering \\ Johns Hopkins University, Baltimore, MD 21205 \\ ${ }^{3}$ Department of Chemical Engineering \\ University of Massachusetts Amherst, Amherst, MA 01003
}

*Tel: (+1)775-784-4697; E-mail: HongfeiL@unr.edu 


\begin{abstract}
The as-synthesized Zr-SBA-15 catalysts with tunable mesoporous structures showed excellent catalytic performance for the conversion of carbohydrates to methyl lactate in a "onepot" process using near- critical methanol or methanol-water mixture as the solvents. The effects of reaction conditions, including temperature, reaction time, and catalyst loading amount, on the conversions of carbohydrates and the yields of methyl lactate were investigated. The high yields of methyl lactate, up to $41 \%$ and $44 \%$, were produced from pentose and hexose, respectively, in the near- critical methanol at $240^{\circ} \mathrm{C}$. Moreover, the $\mathrm{Si} / \mathrm{Zr}$ ratio of the $\mathrm{Zr}-\mathrm{SBA}-15$ catalysts profoundly affected the Lewis acidity and therefore the catalytic activity and selectivity to methyl lactate in the conversion of carbohydrates. The pore size of the Zr-SBA-15 catalysts, tuned by the synthesis temperature, strongly affected the formation of solid residues. The key intermediates such as glyceraldehyde, glycolaldehyde, and pyruvaldehyde were used as probe reactants to understand the mechanism. The role of the Zr-SBA-15 catalyst in the aldol- and retro-aldol condensation, isomerization, and Cannizzaro reactions of carbohydrates and their derivatives was discussed. Furthermore, $28 \%$ and $27 \%$ yields of methyl lactate were obtained from cellulose and starch, respectively, in methanol-water mixture (5 wt $\%$ water and $95 \mathrm{wt} \%$ methanol) at $240^{\circ} \mathrm{C}$. The Zr-SBA-15 catalyst was relatively stable in short term without regeneration.
\end{abstract}

Keywords: Methyl lactate; Carbohydrate biomass; Mesoporous silica; Zr-SBA-15; Lewis acid 


\section{Introduction}

The development of efficient methods to make fuels and chemicals from lignocellulosic biomass is vital to reduce the dependence on fossil fuel feedstocks [1-3]. The production of value-added chemicals from carbohydrates using non-toxic heterogeneous catalysts is an appealing environmentally benign process. Various endeavors have been made over the past few years to develop stable, recyclable solid catalysts for the conversion of biomass by catalytic methods[4-7]. Microporous zeolites are efficient catalysts in the transformation of small molecules; however, they become unsuitable when the essential reactants involved in the catalytic process are sized comparably with the zeolite pore dimensions. The rational approach to overcoming mass-transfer limitations would be to increase the diameter of the pores, thus bringing them into the mesoporous range with a key factor here being the shape selectivity properties of these catalysts [8-13]. Shape selectivity enables excellent adjustment of catalytic transformation exclusivity, and also acts on the activity and stability of the catalyst by either protecting the acid sites from potential contaminants (in particular, coke precursors) which are contained in the feeds, or by inhibiting the formation of coke precursors in the pores. However, few reports exist on biomass conversion with mesoporous silicate materials. This scarcity of literature is due to the fact that a pure mesoporous silica material possesses a neutral framework, as well as its propensity to exhibit inherently negative traits such as poor hydrothermal stability and low catalytic activity, which limit its application as a catalyst medium [14,15]. In order to enable their application in catalysis, different structured mesoporous silicate materials have been investigated and various metal ions have been incorporated into the host mesoporous silica materials [16-20]. In particular, the isomorphic substitution of silicon with transition metals has 
proven to be an excellent strategy to generate catalytically active sites in mesoporous silicate materials [14,21-23].

Among the mesoporous materials, the SBA-15 of 2D hexagonal-ordered structure with tunable pores in 4-10 $\mathrm{nm}$ has received much attention in the past decades due to its relatively large pore size and high hydrothermal stability in comparison with other mesoporous silica materials, such as MCM-41, its analog in M41S family [24]. This large pore channel network provides a distinctive open space, with easy and direct access for both guest and host species, thus facilitating inclusion and/or diffusion throughout the pore channels without pore blockage. Such properties spur the prospective utilization as catalysts and adsorbents $[21,25,26]$. On the other hand, zirconia-based materials have been widely applied in catalyzing various types of reactions such as oxidation, dehydration, hydrogenation, and hydroxylation [27-30]. Mesoporous silicate materials containing zirconium have high special surface areas and potential Lewis acid properties [14,31]. The basic structural unit of mesoporous silicate frameworks consists of a silicon atom that is coordinated to four oxygen atoms. Zirconium atoms have a coordination number of 7 or 8 in zirconia materials. When replacing $\mathrm{Si}^{4+}$ with $\mathrm{Zr}^{4+}$, a zirconium atom has only 4 coordinated oxygen atoms, resulting in empty zirconium d-orbitals which can act as electron acceptors, i.e. Lewis acid sites [32].

Carbohydrates constitute the largest portion of lignocellulosic biomass, and various strategies for their efficient use as a commercial chemical feedstock as a petroleum supplement are being established to synthesize value-added chemicals. The synthesis of lactate acid esters in related alcohols with renewable carbohydrate biomass as the feedstock invokes lots of interests in that lactate acid esters are "green" solvents which have numerous applications in the chemical, food, pharmaceutical, and cosmetic industries [33-37]. Various strategies to produce lactic acid 
esters have been established including both fermentative processes [38] and catalytic transformations $[39,40]$. Catalytic methods have many advantages over that involving fermentation method especially considering the latter approach's unavoidable large amounts of salts by-products, which impose a high environmental remediation cost. Studies on the conversion of carbohydrates to lactate esters over heterogeneous catalysts have emerged recently. For instance, Holm et al. [41,42] reported that Lewis acidic zeotype materials, such as Sn-Beta, catalyzed the conversion of mono- and disaccharides to methyl lactate (ML) in methanol at $160^{\circ} \mathrm{C}$ with a 16 -hour reaction time. With sucrose as the substrate, the ML yield reached a record high of $68 \%$, while when the alkali ion of $\mathrm{K}_{2} \mathrm{CO}_{3}$ was added to the solvent mixture, the ML yield was further promoted to $75 \%$ at $170{ }^{\circ} \mathrm{C}$ [43]. Carlos reported that with the Sn-MCM-41 which has an atomic ratio of $\mathrm{Si} / \mathrm{Sn}=55$, a $43 \%$ yield of $\mathrm{ML}$ was produced from the conversion of glucose after 20 hours at $160^{\circ} \mathrm{C}$ [44]. The carbon-silica composite grafted Sn(IV) showed wellbalanced Lewis/Brønsted acidity and yielded 45\% ML from the conversion of sucrose in methanol[45]. Sn-MWW zeolite was also demonstrated to be an effective and selective catalyst for the direct conversion of mono-and disaccharides to ML[46]. However, the main drawbacks of tin-based materials are the typically complex and lengthy synthesis process and the toxicity of tin precursors, which may hamper their industrial applications[47]. Solid base catalysts, including hydrotalcites [48] and magnesium oxide [49], and supported noble metal catalysts [39] were also used for catalyzing the formation of lactic acid or ML from glucose at rather low yields.

Recently, alcohols have been utilized as an alternative solvent in the liquefaction of various types of biomass, including cellulose, lignin, sewage sludge, and microalgae, due to their advantages with better solubility of organic intermediates, hydrogen donor properties, and easier 
separation due to their low boiling points [50-59]. Compared to water, alcohols such as methanol and ethanol have much lower critical temperatures and pressures. Thus at relatively mild conditions, near- critical and supercritical alcohols can act not only as a solvent but also as a reactant, which can serve as a hydrogen donor agent to remove oxygen from biomass and a radical quenching agent to retard repolymerization and formation of humins [60-63]. Methanol, a small and highly polar molecule, still exhibits weak hydrogen bonding even at the critical temperature $\left(\mathrm{Tc}=239.4^{\circ} \mathrm{C}\right)[64,65]$, which facilitates the methanolysis of large biomass molecules.

Herein we report our findings on the catalytic conversion of carbohydrates to methyl lactate using a mesoporous Zr-SBA-15 catalyst in near- critical methanol solvents $\left(\mathrm{T} \leq 240^{\circ} \mathrm{C}\right.$ ), which combines the lactic acid production and esterification into a "one-pot" reaction system. A possible reaction mechanism and structure-activity relationship are proposed to explain the performance of the Zr-SBA-15 as a heterogeneous Lewis acid catalyst in the production of ML from various carbohydrates including pentose, hexose, starch and cellulose.

\section{Experimental Section}

\subsection{Materials}

The following reagents and products were used as received without further purification. D-(+)-xylose (99\%), D-(+)-glyceraldehyde (98\%), Fructose (99\%), Sucrose (99\%), glycolaldehyde dimer, pyruvaldehyde (40wt\% solution in water), furfural (99\%), 5(hydroxymethyl) furfural (99\%), hydrochloric acid (36.5-38.0\%, BioReagent), triblock copolymer Pluronic P123, tetraethyl orthosilicate (>99.0\%), n-butanol (>99.0\%) and zirconyl chloride octahydrate (98\%) were purchased from Sigma Aldrich. D(+)-Glucose (Reagent ACS Grade) were purchased from Acros Organics. Methyl lactate (97\%), erythrose syrup (70\% w/v), 
methyl levulinate (99\%), methyl glycolate (98\%) and glycolaldehyde dimethylacetal (98\%) were purchased from Alfa Aesar. Microcrystalline cellulose (average particle size $50 \mu \mathrm{m}$ ) and cellobiose (98\%) were purchased from Acros Organics. Starch (powder, certified ACS, soluble) and sucrose (crystalline, certified ACS) were purchased from Fisher Scientific. Galactose, mannose, and arabinose were purchased from Carbosynth.

\subsection{Catalyst preparation}

The Zr-SBA-15 materials were synthesized following the procedure described by reference [24]. Briefly, $2 \mathrm{~g}$ of Pluronic P123 was added to $75 \mathrm{ml}$ of $1.6 \mathrm{M} \mathrm{HCl}$ solution. The mixture was stirred at $40{ }^{\circ} \mathrm{C}$ for 3 hours until all P123 was dissolved. Next, $4.25 \mathrm{~g}$ of TEOS and an appropriate amount of zirconyl chloride octahydrate were added into the solution and the mixture was stirred for another 24 hours at $40^{\circ} \mathrm{C}$. The resulting gel was placed in the Teflonlined autoclave and heated at a range of temperatures of $80-150{ }^{\circ} \mathrm{C}$ for 24 hours. The solid product was filtered with mild washing, dried at $100{ }^{\circ} \mathrm{C}$ overnight, and calcined in flowing air at $550{ }^{\circ} \mathrm{C}$ for 6 hours. The $\mathrm{x}$ (in $\mathrm{Zr}-\mathrm{SBA}-15-\mathrm{x}-\mathrm{y}^{\circ} \mathrm{C}$ ) represents the mole ratio of $\mathrm{Si} / \mathrm{Zr}$, the $\mathrm{y}$ represents the hydrothermal temperature. $\mathrm{Zr}-\mathrm{SBA}-15-\mathrm{y}^{\circ} \mathrm{C}$ without $\mathrm{x}$ means that the mole ratio of $\mathrm{Si} / \mathrm{Zr}$ is 20 . Zr-SBA-15-x without y means that the catalyst was synthesized at $100^{\circ} \mathrm{C} . \mathrm{Zr}-\mathrm{SBA}-$ 15 without $\mathrm{x}$ and $\mathrm{y}$ means that the catalyst was synthesized at $100^{\circ} \mathrm{C}$ with $\mathrm{Si} / \mathrm{Zr}=20$.

\subsection{Catalyst characterization:}

Small-angle X-ray Scattering (SAXS) was performed using a sample-to-detector distance of $172.1 \mathrm{~cm}$, which provided a two-theta range of approximately 0.3-2.0 degrees. Data was typically collected over 30 seconds at a temperature of $20^{\circ} \mathrm{C}$. The X-ray source was $\mathrm{Cu} \mathrm{Ka}$ radiation with a wavelength of $1.54 \AA$, which was generated by a Rigaku Ru-200BVH rotating 
anode. Measurements were made on a Siemens HI-STAR multi-wire area detector and were corrected for background and non-linearities in the detector. Integration of the 2D measurement provided a 1D plot of intensity (arbitrary units) versus the two-theta scattering angle, which was peak-fitted using Material Data Incorporated's JADE.

Transmission electron microscope (TEM) micrographs were captured using JEOL-JEM $2100 \mathrm{~F}$ operating at $200 \mathrm{kV}$. The samples were dispersed in 1-butanol, and a drop of the suspension was placed on lacey carbon supported on 300 mesh copper grids.

$\mathrm{N}_{2}$ physisorption isotherms were measured on an Autosorb-iQ system (Quantachrome) at $77 \mathrm{~K}$. Outgassing was done at $523 \mathrm{~K}$ until pressure rise in the test cell was less than 25 mTorr/min. Pore size distribution and cumulative adsorbed volume were calculated by using NLDFT (nonlocal density functional theory) adsorption model which describes $\mathrm{N}_{2}$ adsorbed onto silica at $77 \mathrm{~K}$ in cylindrical pores (AsiQwin 1.02, Quantachrome). NLDFT model considers the configuration of adsorbates in pores on a molecular level and is widely used to characterize ordered porous materials with different pore geometries. With adequate fluid-fluid and fluid-solid interaction parameters, it has been used to quantitatively predict the capillary condensation and evaporation transitions of adsorbates in mesoporous materials.

In a typical $\mathrm{NH}_{3}$ temperature programmed desorption (TPD) experiment using a Micromeritics AutoChem $\square \square 2920$ Chemisorption Analyzer the catalyst was first degassed in helium at $250^{\circ} \mathrm{C}$ for 1 hour, then the temperature was cooled till $100^{\circ} \mathrm{C}$ in helium flow. After that, $10 \%$ ammonia in helium was adsorbed on the catalyst at $100^{\circ} \mathrm{C}$ for $60 \mathrm{~min}$ and then the helium flow at $50 \mathrm{~mL} / \mathrm{min}$ was used to remove physically adsorbed ammonia. Finally, the $\mathrm{NH}_{3}$ TPD was carried out from $100^{\circ} \mathrm{C}$ to $550^{\circ} \mathrm{C}$ with a temperature ramp of $10^{\circ} \mathrm{C} / \mathrm{min}$.

Drift-IR study was performed on EQUINOX 55 (Bruker) equipped with a MCT 
detector. The samples were degassed at $550^{\circ} \mathrm{C}$ for 1 hour under helium in a high temperature reaction chamber containing a Praying Mantis ${ }^{\mathrm{TM}}$ diffuse reflection attachment (Harrick). Small aliquots of pyridine were carried by helium and exposed to the sample at room temperature for 15 minutes. Prior to the characterization, the physically adsorbed pyridine was removed by flowing helium at $250^{\circ} \mathrm{C}$ under helium for 1 hour. All spectra were collected at $120^{\circ} \mathrm{C}$.

\subsection{Catalytic reactions}

Reactions were carried out in a $100 \mathrm{~mL}$ stirred Parr micro reactor, whereby the catalyst was suspended in a solution of biomass substrate in methanol $(20 \mathrm{ml})$ and the reactor was charged with 400 Psi $\mathrm{N}_{2}$ initially and then heated at a ramp rate of $10{ }^{\circ} \mathrm{C} / \mathrm{min}$ until the desired set temperature was reached. During the reaction, mixing was achieved through an internal propeller operating at $700 \mathrm{RPM}$. Once the set temperature was attained, the reactor was held for the set reaction time, and then quenched quickly in an ice bath to stop the reaction. The reactor was cooled to approximately $25^{\circ} \mathrm{C}$ before being vented after the gas pressure was recorded. The reactor was then immediately broken down and the solid residue remaining in the reactor was recovered and dried. The aqueous and solid fractions were separated using a centrifuge.

\subsection{Product analysis}

After the reaction, the resultant liquid phase product samples were prepared for analysis with a gas chromatography coupling with flame ionization detector (GC-FID), a high performance liquid chromatography (HPLC) and a gas chromatography coupling with mass spectrometer (GC-MS).

The liquid products (e.g. furfural, HMF) were quantified by HPLC analysis using a Shimadzu HPLC system equipped a UV-VIS Detector (Shimadzu SPD 10-AV) and Refractive Index Detector (Shimadzu RID-6A). The liquid phase after reaction was filtered through a 0.45 
micron syringe filter, and then diluted 10 times with DI water. The samples were separated in an Aminex $87-\mathrm{H}$ column from Bio-Rad, using $5 \mathrm{mM} \mathrm{H}_{2} \mathrm{SO}_{4}$ as the mobile phase $(0.7 \mathrm{~mL} / \mathrm{min}$ flow rate) at a column temperature of $55^{\circ} \mathrm{C}$. The UV-VIS detector was utilized at $208 \mathrm{~nm}$ and $290 \mathrm{~nm}$.

The liquid products identified in the methanol were qualified and quantified by GC-MS and GC-FID analysis, respectively. The liquid phase after reaction was filtered through a 0.45 micron syringe filter before being diluted 10 times with methanol. The sample were injected in an Agilent 6890 series GC-MS equipped with an Agilent DB5-MS column (30 m x 0.25 mm ID, 0.25 um film thickness) and an Agilent 5973 Mass Selective Detector. The same prepared sample were also injected in a Shimadzu GC-2010 equipped with an SHRXI-5MS column (30m x $0.25 \mathrm{~mm}$ ID, 0.25 um film thickness) and an FID detector.

A Euro EA3000 CHNS-O analyzer (Eurovector) was used for measuring the carbon content in the solid residue samples.

\section{Results and discussion}

Fig. 1 shows the yields of the main products using xylose as the feedstock with and without adding catalysts. A relatively low yield of $\mathrm{ML}(\sim 8 \%)$ was produced at $240^{\circ} \mathrm{C}$ without adding a catalyst. With only the pure SBA-15, the ML yield was $\sim 7.0 \%$, which is close to that without catalyst. Both the as-synthesized $\mathrm{Zr}-\mathrm{SBA}-15$ and the commercial $\mathrm{ZrO}_{2}$ resulted in noticeably higher yields of ML at $240^{\circ} \mathrm{C}$ for 1 hour. The $35.9 \%$ yield of ML was achieved with the Zr-SBA-15 catalyst, which was more than twice of the $16.4 \%$ yield with the $\mathrm{ZrO}_{2}$ catalyst. To validate the catalytic effect of $\mathrm{Zr}$ ion in SBA-15, Ti ions were deliberately incorporated into the SBA-15 framework so as to compare with the Zr-SBA-15 catalyst. It was found that with the Ti-SBA-15 catalyst, the yield of ML from xylose was comparable to that with the $\mathrm{ZrO}_{2}$ catalyst but was still much lower than that with the Zr-SBA-15 catalyst. Notably, without a catalyst or 
with the Ti-SBA-15 catalyst, there were negligible amount of furfural yields, $0.7 \%$ and $0.8 \%$, respectively. In contrast, when SBA-15, $\mathrm{ZrO}_{2}$ and $\mathrm{Zr}-\mathrm{SBA}-15$ were employed, the furfural yields reached to $5.1 \%, 6.4 \%$ and $7.9 \%$, respectively. The mesoporous structure of the silica framework with the presence of zirconium ions confers strong Lewis acidity as well as weak Brønsted acidity.[66] It is well accepted that Lewis acid catalysis can facilitate the retro-aldol condensation of a sugar molecule, which is the initial step in the conversion of sugars to lactic acid [41], while a Brønsted acid catalyzes the dehydration of xylose to form furfural. The coproduction of ML and furfural from xylose with the Zr-SBA-15 catalyst suggest that both the Lewis and Brønsted acidic properties co-existed on the catalyst surface.

To further examine the catalytic effect of zirconium loading of the Zr-SBA-15 catalyst, the catalysts with different $\mathrm{Si} / \mathrm{Zr}$ molar ratios of $100,60,40,20$ and 10 were prepared. As shown in Fig. 2, the total acid strength analysed by the $\mathrm{NH}_{3}$ TPD increased with increasing the zirconium loading on the SBA-15 silicate. Fig. 3 shows the yields of the three major products, ML, glycoladehyde dimethyl acetal (GADMA), and furfural, on the Zr-SBA-15 catalysts with various $\mathrm{Si} / \mathrm{Zr}$ molar ratios under otherwise identical reaction conditions. Initially, with increasing the $\mathrm{Zr}$ loading, the yields of increased steadily. However, as the zirconia loading further increased till the $\mathrm{Si} / \mathrm{Zr}$ mole ratio of 10 , the yields of all three products decreased implying the abrupt change of the catalyst properties. The maximum yield of ML was found to be in the range of the Si/Zr mole ratios of 40 to 20 , e.g., with the Zr-SBA-15-40 or Zr-SBA-1520 catalyst, approximately $19 \% \mathrm{ML}$ and $11 \%$ GADMA were produced at $180^{\circ} \mathrm{C}$. However overloading of Zr ions onto SBA-15 inhibited the catalyst's performance. Therefore, to confirm the structures of the Zr-SBA-15 silicate materials at different $\mathrm{Si} / \mathrm{Zr}$ ratios, the small-angle $\mathrm{X}$-ray scattering (SAXS) characterization was performed. As depicted in Fig. 4, the SAXS spectra 


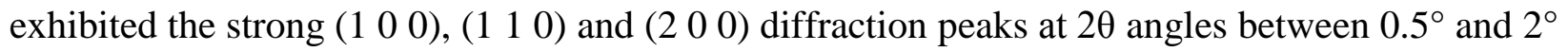
for the samples with the Si/Zr ratios from 100 to 20, which indicated the structural ordering with the symmetry of the 2D-hexagonal space group p6mm[9,14,31]. However, a further increase in $\mathrm{Zr}$ loading $(\mathrm{Si} / \mathrm{Zr}=10)$ drastically lowered the peak intensity suggesting that incorporating too many $\mathrm{Zr}$ heteroatoms was detrimental on the structure of the mesoporous SBA-15 framework, which was coincident with its low catalytic performance. From the high-resolution TEM images (Fig. S1), highly ordered pore structure was evident for the Zr-SBA-15 materials at the Si/Zr mole ratio of 20, while the ordered mesoporous structure was destroyed when the Si/Zr mole ratio reached 10, which were consistent with the SAXS data.

To maximize ML yield, process conditions were optimized for the xylose conversion reactions. As shown in Fig. 5, the varying temperature has a pronounced effect on the production of ML, yielding a steadily increasing amount of ML up to $35.9 \%$ with an increase in temperature from $160^{\circ} \mathrm{C}$ to $240^{\circ} \mathrm{C}$ for a 1 -hour reaction. The yields of other products such as furfural also increased steadily with increasing temperature. The yield of GADMA, however, decreased from $10.9 \%$ at $180^{\circ} \mathrm{C}$ to $1.6 \%$ at $240^{\circ} \mathrm{C}$. The highest ML yield of $40.8 \%$ was achieved when the reaction time extended to 6 hours at $240^{\circ} \mathrm{C}$ as shown in Fig. 6. However, the ML yield varied little as the reaction time was longer than 3 hours. Conversely, the yields of GADMA and furfural consistently decreased with extending the reaction time. Of particular interest is the fact that GADMA almost completely vanished after 3 hours at $240^{\circ} \mathrm{C}$. These results suggested that longer reaction time leads to the decomposition of GADMA and furfural. It is also interesting to find that the methyl levulinate yield increased with reaction time at $240^{\circ} \mathrm{C}$. The effects of different catalyst loading amounts on the conversion of xylose were also examined. As depicted in Fig. 7, the yields of both ML and furfural showed a similar uptrend with constantly increasing 
catalyst loading, while those of GADMA and methyl glycolate decreased steadily. However, as the mass ratio of catalyst to xylose was larger than 0.2 , the yield of ML was almost unchanged and reached to a plateau. By substituting methanol with water as the solvent (Table 3 entry 4), the lactic acid yield was $\sim 5.9 \%$ while the furfural yield was $\sim 42.3 \%$ with $\mathrm{Zr}-\mathrm{SBA}-15$. In contrast, the yields of furfural and lactic acid were only $21.2 \%$ and $3.0 \%$, respectively, without adding any catalyst. Thus the Lewis acid property of the Zr-SBA-15 catalyst appeared to vanish and be transformed to Bronsted acid in water.

For chemical reactions in confined channel space in mesoporous silicate materials, interesting pore size effects can be expected.[67-69] The pore size of the Zr-SBA-15 catalyst can be tuned by optimizing the hydrothermal treatment conditions during the synthesis.[70] Fig.8 shows the pore size distribution determined by NLDFT model for the Zr-SBA-15 materials with different synthesis temperatures. The pore sizes of $\mathrm{Zr}-\mathrm{SBA}-15-80^{\circ} \mathrm{C}, \mathrm{Zr}-\mathrm{SBA}-15-100^{\circ} \mathrm{C}, \mathrm{Zr}-$ SBA- $15-120^{\circ} \mathrm{C}$ and $\mathrm{Zr}-\mathrm{SBA}-15-150^{\circ} \mathrm{C}$, were $7.6,9.1,9.8$ and $10.6 \mathrm{~nm}$, respectively. With increasing the hydrothermal temperature, the pore diameter of the SBA-15 materials increased while the BET surface area decreased. The ML yield varied slightly with increasing the pore size except the catalyst synthesized at $80^{\circ} \mathrm{C}$ in the smallest pore size, as shown in Table 1. In contrast, the furfural yield and the corresponding solid residue yield decreased significantly with increasing the pore size. It is well known that aldehyde compounds such as furfural are prone to polymerize and form humins at elevated temperatures. Apparently, large pores in a Zr-SBA-15 catalyst provides more open pore space where guest and host species can easily access, thus facilitating the diffusion in and out the stoma channels without pore restriction. It turns out that in order to minimize the undesirable by-products such as furfural and humins, it is important to lift the pore diffusion limit of the Zr-SBA-15 catalyst for this particular ML production reaction. 
Recyclability and reusability are of importance for the heterogeneous Zr-SBA-15 catalysts. During the typical reaction, the yield of solid residue on the catalyst was relatively low, $\sim 10.8 \%$. However, the activity of the catalyst could decrease if solid residue continues to build up on the catalyst surface in the subsequent repeating reactions. Fig.9 shows that the yield of ML from xylose only decreased slightly over five consecutive runs with the re-used catalyst without regeneration, suggesting that the Zr-SBA-15 catalyst was relatively stable, although a regeneration process to remove the solid residues would be desirable for the catalyst re-use. It is very interesting to find that the yield of solid residue $(10.7 \%)$ on the catalyst after the $5^{\text {th }}$ run almost did not change compared with that after the first run (10.8\%), implying that the formation of extra coke inside the pores was inhibited after the catalyst was used once. The high-resolution TEM images of the Zr-SBA-15 samples before and after reaction showed that the highly ordered pore structure maintained without any noticeable pore size shrinkage or blockage, as shown in Fig. 10. Furthermore, ML was used as reactant to test its stability. It was found that only $3 \%$ of ML was decomposed after a one-hour reaction at $240^{\circ} \mathrm{C}$ with the $\mathrm{Zr}$-SBA-15 catalyst in methanol (Fig. S2), thus indicating that ML, the final product of xylose conversion, was very stable in this reaction system.

It is well accepted that Lewis acids can promote retro-aldol condensation as the initial step in the conversion of sugars to lactic acid [41]. We thus propose that the reaction pathway of converting xylose to ML over the Zr-SBA-15 catalyst begins at the retro-aldol condensation forming glycolaldehyde and glyceraldehyde, as shown in Scheme 1. Fig. S3 illustrates the total acidity of the Zr-SBA-15 samples calculated from the $\mathrm{NH}_{3}$ TPD. The pure SBA-15 silicate did not show any appreciable ammonia adsorption (only $0.02 \mathrm{mmol} \mathrm{NH}_{3} / \mathrm{g}$ ), while the $\mathrm{Zr}-\mathrm{SBA}-15$ samples presented high acidity of $\sim 0.7 \mathrm{mmol} \mathrm{NH}_{3} / \mathrm{g}$. In our previous study, it was confirmed by 
the pyridine-FTIR that the Lewis acid sites were dominant on the $\mathrm{Zr}-\mathrm{SBA}-15$ catalyst. The $\mathrm{Zr}^{4+}$ ions in the SBA-15 silica framework as the Lewis acid sites first interacted with the carbonyl group of xylose, and then broke the C5 xylose molecule down to C3 glyceraldehyde and C2 glycolaldehyde. Glyceraldehyde underwent dehydration to form 2-hydroxypropenal, then to pyruvaldehyde via keto-enol tautomerization, and finally to ML in methanol solvent by possible intramolecular Cannizzaro and esterification reactions. Although trioses were able to be converted to ML via Meerwein-Ponndorf-Verley reduction with methanol[71], the direct evidence of converting pyruvaldehyde to ML through intramolecular Cannizzaro reaction was that no deuterium was incorporated into the hydrocarbon backbone of $\mathrm{ML}$ in the isotopic $\mathrm{CD}_{3} \mathrm{OD}$ solvent [72]. On the other hand, the by-product, GADMA, was formed by the acetalization of glycolaldehyde with methanol.

To validate our hypothesis of the reaction pathway, the possible key intermediates, glyceraldehyde, dihydroxyacetone, pyruvaldehyde, glycolaldehyde, and GADMA were used as the probe reactants. It was found that much higher ML yields (78.8\% and $84.5 \%)$ were obtained from glyceraldehyde and dihydroxyacetone, respectively (Table 3 Entries 6 and 8), than from xylose. The yield of ML was even close to $100 \%$ from pyruvaldehyde (Table 3 Entry 10). Yet in the absence of the Zr-SBA-15, much lower amounts of ML were produced from all three probe reactants. More interestingly, using glycolaldehyde as the probe, a high amount of GADMA was produced without catalyst, while $\sim 61.3 \% \mathrm{ML}$ was obtained with the Zr-SBA-15 catalyst. It appeared that $\mathrm{C}-\mathrm{C}$ bond forming aldol condensation reactions occurred in the presence of $\mathrm{Zr}$ SBA-15 in that the C4 acid ester products, e.g., methyl vinylglycolate and methyl 2hydroxybutanoate, were also observed as the products from the $\mathrm{C} 2$ reactant, glycolaldehyde (Fig. S4). Very interestingly, when using GADMA as the probe reactant, it was converted to ML in a 
$24 \%$ yield with the $\mathrm{Zr}-\mathrm{SBA}-15$ catalyst and the product distribution was similar to that using glycolaldehyde as the reactant: methoxyacetaldehyde dimethylacetal was another major product obtained through etherification while other products in the much lower yields were methyl vinylglycolate and methyl 2-hydroxybutanoate, as shown in Fig. S5. It revealed that GADMA and glycoaldehyde were reversibly converted to each other and the aldol-condensation reactions occurred in the presence of $\mathrm{Zr}$-SBA-15 to form $\mathrm{C} 4$ and $\mathrm{C} 6$ aldehydes, while the formation of ML suggested that retro-aldol condensation reactions took place subsequently. However, it is unclear how the etherification and esterification reactions with methanol evolved in parallel to the aldo condensation and retro- aldo condensation reactions. Since most glycolaldehyde intermediates could be further converted to ML with the Zr-SBA-15 catalyst in near critical methanol, the yields of ML from pentoses (xylose, arabinose) and hexoses (glucose, mannose) had no distinct difference, unlike the results of converting sugars to $\mathrm{ML}$ at $160-170^{\circ} \mathrm{C}$ using the Sn-Beta catalyst reported by Taarning and co-workers [42].

Furfural was the undesirable by-product from the dehydration of xylose, usually catalyzed by Brønsted acid. The furfural yield decreased sharply at high temperatures or for a long reaction time, while methyl levulinate yield increased at the same time during the xylose conversion with the Zr-SBA-15 catalyst. Using furfural as the probe reactant, the main product was methyl levulinate in the yields of $3.6 \%$ and $33.2 \%$ after reactions for 1 hour and 10 hours, respectively, at $240^{\circ} \mathrm{C}$, as shown in Fig. S6. Alkyl levulinate is known to be produced from furfuryl alcohol with solid acid catalyst [73]. A hydrogenation step is needed in the conversion of furfural to methyl levulinate, while methanol was the only hydrogen source in the probe reaction. We thus contemplate that furfural was converted into furfuryl alcohol via MeerweinPonndorf-Verley (MPV) transfer hydrogenation with methanol as the hydrogen donor, which 
was probably promoted by the Lewis acid, followed by the conversion of furfuryl alcohol into methyl levulinate through ring-opening reactions with the aid of the weak Brønsted acid sites on the Zr-SBA-15 catalyst. Corma's group demonstrated the intermolecular transfer hydrogenation between alcohols and ketones in organic solvents using Sn-Beta and Zr-Beta as the solid Lewis acid catalysts [74-76].

The proposed reaction pathway for the conversion of xylose to ML can be generalized for the conversion of other cellulosic biomass. The retro-aldol condensation of pentoses and hexoses, however, may form different aldehyde or ketone products with solid Lewis acid catalysts [41,42]. The conversion of pentoses to ML can be divided as the following steps: retro-aldol condensation of an aldopentose leads to glyceraldehyde and glycolaldehyde, while retro-aldol condensation of a ketopentose forms dihydroxyacetone and glycolaldehyde. The outcome of both reaction pathways is the formation of a triose and a glycolaldehyde [42]. In contrast, the fragments formed from a hexose depend on the ketose or aldose form. Disintegration of an aldohexose leads to the fragments of a C4 aldotetrose and a C2 glycolaldehyde, while the ketohexose fragmentation results in two C3 fragments, dihydroxyacetone and glyceraldehyde [41]. With a Lewis acid catalyst, however, glucose and fructose can be inter-converted through isomerization before experiencing subsequent reactions $[44,77]$. Table 3 shows that the disparate yields of ML were produced from glucose and fructose, respectively, while the comparable yields are seen for fructose and sucrose, the dimer of glucose and fructose (products were identified by GC/MS as shown in Fig. S7). Glucose yielded a lower amount of ML relative to fructose $(37.3 \%$ versus $44.1 \%)$. The difference in the ML yields from different monosaccharides reflects the dynamic equilibrium between the isomerization, retro-aldol condensation and degradation reactions. In all cases, the conversions of both monosaccharides and disaccharides 
were greater than $99 \%$ after 6 hours of reaction at $240{ }^{\circ} \mathrm{C}$ and the considerable yields of ML were formed using the Zr-SBA-15 catalyst (Table 3). Using disaccharides or polysaccharide including cellobiose, starch and cellulose as the reactants, substantially lower conversions were observed (products were identified by GC/MS as shown in Fig. S8). Cellobiose and starch, which are soluble in methanol, reached the similar yields of ML, $24.3 \%$ and $24.1 \%$, respectively. However, only $16.7 \% \mathrm{ML}$ was produced from cellulose at $240^{\circ} \mathrm{C}$ for a 10 hours reaction, suggesting that depolymerization is the bottleneck for cellulose conversion. In order to enhance the yield of ML from cellulose, a small amount of water (5 wt\%) was added into methanol to facilitate the hydrolysis of cellulose. As the result, as high as $28.1 \%$ yield of ML was obtained directly from cellulose.

\section{Conclusion}

In summary, we demonstrate that methyl lactate was yielded from various carbohydrates in methanol solutions at near critical conditions with the Zr-SBA-15 catalysts. Under the optimum reaction conditions, the highest methyl lactate yields were $42 \%$ and $44 \%$ from pentoses and hexoses, respectively. The Zr-SBA-15 catalyst was relatively stable to produce methyl lactate from xylose after five consecutive catalytic reaction cycles without regeneration. The Lewis acid sites on the Zr-SBA-15 facilitated the retro-aldol condensation of carbohydrates, which was the initial step of the conversion of carbohydrates to methyl lactate. Increasing zirconium loading on the SBA-15 silica framework increased the total acid strength of the $\mathrm{Zr}$ SBA-15 catalyst. However, over-load of zirconium could destroy the mesoporous structure of the SBA-15 silica. The large-pore Zr-SBA-15 catalysts inhibited the yields of undesirable byproducts such as humins and furfural. Through the probe reaction studies, we conclude that $\mathrm{C} 3$ aldehydes/ketones including glyceraldehyde, dihydroxyketone, and perualdehyde were the key 
intermediates to form methyl lactate from a variety of carbohydrate biomass. Zr-SBA-15 also catalyzed aldol condensation of C2 aldehydes to form C4 and C6 sugars, followed by subsequent retro-aldol condensation, and finally to produce methyl lactate in high yields. The conversions of polysaccharides such as starch and cellulose are much more challenging than those of monosaccharides and thus longer reaction time, as well as adding water co-solvent to facilitate the hydrolysis, was beneficial. Overall, this "one-pot" process using the Zr-SBA-15 catalyst and near critical methanol solvent is efficient and environmentally-friendly to produce ML from cellulosic biomass feedstocks.

\section{Acknowledgement}

This material is based upon work supported by the National Science Foundation under Grant No. CBET 1337017. The authors would like to thank Dr. Jacob Warner of the University of Minnesota Characterization Facility for the SAXS measurements, Dr. Steven Spain for the support of the analytical instruments in the Shared Instrumentation Laboratory (SIL) in Chemistry department of UNR, and Dr. Mojtaba Ahmadiantehrani in the Chemical and Materials Engineering Department for the TEM test. 


\section{Reference:}

[1] D.J. Braden, C.A. Henao, J. Heltzel, C.C. Maravelias, J.A. Dumesic, Production of liquid hydrocarbon fuels by catalytic conversion of biomass-derived levulinic acid, Green Chem. 13 (2011) 1755-1765.

[2] B. Girisuta, Levulinic acid from lignocellulosic biomass, University of Groningen, 2007.

[3] J.A. Geboers, S. Van de Vyver, R. Ooms, B. Op de Beeck, P.A. Jacobs, B.F. Sels, Chemocatalytic conversion of cellulose: opportunities, advances and pitfalls, Catal. Sci. Technol. 1 (2011) 714-726.

[4] H. Deng, L. Lin, S. Liu, Catalysis of cu-doped co-based perovskite-type oxide in wet oxidation of lignin to produce aromatic aldehydes, Energy \& Fuels. 24 (2010) 4797-4802.

[5] W. Deng, Y. Wang, Q. Zhang, Y. Wang, Development of bifunctional catalysts for the conversions of cellulose or cellobiose into polyols and organic acids in water, Catal. Surv. from Asia. 16 (2012) 91-105.

[6] J. Hegner, K.C. Pereira, B. DeBoef, B.L. Lucht, Conversion of cellulose to glucose and levulinic acid via solid-supported acid catalysis, Tetrahedron Lett. 51 (2010) 2356-2358.

[7] J. Jow, G.L. Rorrer, M.C. Hawley, D.T.A. Lamport, Dehydration of d-fructose to levulinic acid over LZY zeolite catalyst, Biomass. 14 (1987) 185-194.

[8] R. Mellaerts, C.A. Aerts, J. Van Humbeeck, P. Augustijns, G. Van den Mooter, J.A. Martens, Enhanced release of itraconazole from ordered mesoporous SBA-15 silica materials., Chem. Commun. (2007) 1375-1377.

[9] A. Katiyar, S. Yadav, P.G. Smirniotis, N.G. Pinto, Synthesis of ordered large pore SBA15 spherical particles for adsorption of biomolecules., J. Chromatogr. A. 1122 (2006) 1320 .

[10] P. Valle-vigón, M. Sevilla, A.B. Fuertes, Sulfonated mesoporous silica - carbon composites and their use as solid acid catalysts, Appl. Surf. Sci. 261 (2012) 574-583.

[11] R. Koster, B. Van Der Linden, E. Poels, A. Bliek, The mechanism of the gas-phase esterification of acetic acid and ethanol over MCM-41, J. Catal. 204 (2001) 333-338.

[12] I. Agirrezabal-Telleria, J. Requies, M.B. Güemez, P.L. Arias, Dehydration of d-xylose to furfural using selective and hydrothermally stable arenesulfonic SBA-15 catalysts, Appl. Catal. B Environ. 145 (2014) 34-42.

[13] C.R. Marcilly, Where and how shape selectivity of molecular sieves operates in refining and petrochemistry catalytic processes, Top. Catal. 13 (2000) 357-366. 
[14] S.-Y. Chen, J.-F. Lee, S. Cheng, Pinacol-type rearrangement catalyzed by Zr-incorporated SBA-15, J. Catal. 270 (2010) 196-205.

[15] T.S. Jiang, X.P. Zhou, Y.H. Li, Q. Zhao, H.B. Yin, Characterization of Zr-based MCM-41 mesoporous molecular sieves obtained by microwave irradiation or hydrothermal method, Inorg. Mater. 47 (2011) 296-302.

[16] J. Zhu, Q. Gao, Z. Chen, Preparation of mesoporous copper cerium bimetal oxides with high performance for catalytic oxidation of carbon monoxide, Appl. Catal. B Environ. 81 (2008) 236-243.

[17] S. Lima, M.M. Antunes, A. Fernandes, M. Pillinger, M.F. Ribeiro, A.A. Valente, Acidcatalysed conversion of saccharides into furanic aldehydes in the presence of threedimensional mesoporous Al-TUD-1, Molecules. 15 (2010) 3863-3877.

[18] M.S. Morey, S.O. Brien, S. Schwarz, G.D. Stucky, Hydrothermal and postsynthesis surface modification of cubic, MCM-48, and ultralarge pore SBA-15 mesoporous silica with titanium, Chem. Mater. 12 (2000) 898-911.

[19] Q. Pan, Intrinsic kinetics of lower alcohols: C2, C3 dehydration over Lewis acidic ordered mesoporous silicate: Zr-KIT-6, University of Kansas, 2013.

[20] T.W. Kim, F. Kleitz, B. Paul, R. Ryoo, MCM-48-like large mesoporous silicas with tailored pore structure: Facile synthesis domain in a ternary triblock copolymer-butanolwater system, J. Am. Chem. Soc. 127 (2005) 7601-7610.

[21] Q. Pan, A. Ramanathan, W.K. Snavely, R. V. Chaudhari, B. Subramaniam, Synthesis and dehydration activity of novel Lewis Acidic ordered mesoporous silicate: Zr-KIT-6, Ind. Eng. Chem. Res. 52 (2013) 15481-15487.

[22] F. Bérubé, B. Nohair, F. Kleitz, S. Kaliaguine, Controlled postgrafting of titanium chelates for improved synthesis of Ti-SBA-15 epoxidation catalysts, Chem. Mater. 22 (2010) 1988-2000.

[23] T. Tsoncheva, L. Ivanova, J. Rosenholm, M. Linden, Cobalt oxide species supported on SBA-15, KIT-5 and KIT-6 mesoporous silicas for ethyl acetate total oxidation, Appl. Catal. B Environ. 89 (2009) 365-374.

[24] S.Y. Chen, L.Y. Jang, S. Cheng, Synthesis of Zr-incorporated SBA-15 mesoporous materials in a self-generated acidic environment, Chem. Mater. 16 (2004) 4174-4180.

[25] A. Prabhu, L. Kumaresan, M. Palanichamy, V. Murugesan, Synthesis and characterization of aluminium incorporated mesoporous KIT-6: efficient catalyst for acylation of phenol, Appl. Catal. A Gen. 360 (2009) 59-65. 
[26] A. Vinu, N. Gokulakrishnan, V. V Balasubramanian, S. Alam, M.P. Kapoor, K. Ariga, et al., Three-dimensional ultralarge-pore ia3d mesoporous silica with various pore diameters and their application in biomolecule immobilization, Chem. A Eur. J. 14 (2008) 1152911538 .

[27] L. Yang, J. Su, S. Carl, J.G. Lynam, X. Yang, H. Lin, Catalytic conversion of hemicellulosic biomass to lactic acid in $\mathrm{pH}$ neutral aqueous phase media, Appl. Catal. B Environ. 162 (2015) 149-157.

[28] Y. Zhu, S. Jaenicke, G.K. Chuah, Supported zirconium propoxide - A versatile heterogeneous catalyst for the Meerwein-Ponndorf-Verley reduction, J. Catal. 218 (2003) 396-404.

[29] H. Lin, J. Strull, Y. Liu, Z. Karmiol, K. Plank, G. Miller, et al., High yield production of levulinic acid by catalytic partial oxidation of cellulose in aqueous media, Energy Environ. Sci. 5 (2012) 9773-9777.

[30] Y. Zhu, S. Liu, S. Jaenicke, G. Chuah, Zirconia catalysts in Meerwein-Ponndorf-Verley reduction of citral, Catal. Today. 97 (2004) 249-255.

[31] L. Fuxiang, Y. Feng, L. Yongli, L. Ruifeng, X. Kechang, Direct synthesis of Zr-SBA-15 mesoporous molecular sieves with high zirconium loading: characterization and catalytic performance after sulfated, Microporous Mesoporous Mater. 101 (2007) 250-255.

[32] E. Rodríguez-Castellón, A. Jiménez-López, P. Maireles-Torres, D. Jones, J. Rozière, M. Trombetta, et al., Textural and structural properties and surface acidity characterization of mesoporous silica-zirconia molecular sieves, J. Solid State Chem. 175 (2003) 159-169.

[33] H. Kishida, F. Jin, X. Yan, T. Moriya, H. Enomoto, Formation of lactic acid from glycolaldehyde by alkaline hydrothermal reaction, Carbohydr. Res. 341 (2006) 2619-2623.

[34] R.H.W. Maas, R.R. Bakker, G. Eggink, R.A. Weusthuis, Lactic acid production from xylose by the fungus Rhizopus oryzae, Appl. Microbiol. Biotechnol. 72 (2006) 861-868.

[35] L. Wang, B. Zhao, B. Liu, B. Yu, C. Ma, F. Su, et al., Efficient production of 1-lactic acid from corncob molasses, a waste by-product in xylitol production, by a newly isolated xylose utilizing Bacillus sp. strain., Bioresour. Technol. 101 (2010) 7908-7915.

[36] X. Yan, F. Jin, K. Tohji, A. Kishita, H. Enomoto, Hydrothermal conversion of carbohydrate biomass to lactic acid, AIChE J. 56 (2010) 2727-2733.

[37] Y. Fan, C. Zhou, X. Zhu, Selective catalysis of lactic acid to produce commodity chemicals, Catal. Rev. 51 (2009) 293-324. 
[38] M.E. Himmel, S.-Y. Ding, D.K. Johnson, W.S. Adney, M.R. Nimlos, J.W. Brady, et al., Biomass recalcitrance: engineering plants and enzymes for biofuels production, Science. 315 (2007) 804-807.

[39] A. Onda, T. Ochi, K. Kajiyoshi, K. Yanagisawa, A new chemical process for catalytic conversion of d-glucose into lactic acid and gluconic acid, Appl. Catal. A Gen. 343 (2008) 49-54.

[40] L. Kong, G. Li, H. Wang, W. He, F. Ling, Hydrothermal catalytic conversion of biomass for lactic acid production, J. Chem. Technol. Biotechnol. 388 (2008) 383-388.

[41] M.S. Holm, S. Saravanamurugan, E. Taarning, Conversion of sugars to lactic acid derivatives using heterogeneous zeotype catalysts, Science. 328 (2010) 602-605.

[42] M.S. Holm, Y.J. Pagán-Torres, S. Saravanamurugan, A. Riisager, J. a. Dumesic, E. Taarning, Sn-Beta catalysed conversion of hemicellulosic sugars, Green Chem. 14 (2012) 702-706.

[43] S. Tolborg, I. Sádaba, C.M. Osmundsen, P. Fristrup, M.S. Holm, E. Taarning, Tincontaining silicates: alkali salts improve methyl lactate yield from sugars, ChemSusChem. 8 (2015) 613-617.

[44] B. Murillo, A. Sánchez, V. Sebastián, C. Casado-Coterillo, O. de la Iglesia, M.P. LópezRam- de-Viu, et al., Conversion of glucose to lactic acid derivatives with mesoporous SnMCM-41 and microporous titanosilicates, J. Chem. Technol. Biotechnol. 89 (2014) 13441350 .

[45] F. de Clippel, M. Dusselier, R. Van Rompaey, P. Vanelderen, J. Dijkmans, E. Makshina, et al., Fast and selective sugar conversion to alkyl lactate and lactic acid with bifunctional carbon-silica catalysts, J. Am. Chem. Soc. 134 (2012) 10089-10101.

[46] Q. Guo, F. Fan, E.A. Pidko, W.N.P. van der Graaff, Z. Feng, Can Li, et al., Highly active and recyclable Sn-MWW zeolite catalyst for sugar conversion to methyl lactate and lactic acid, ChemSusChem. 6 (2013) 1352-1356.

[47] P.Y. Dapsens, C. Mondelli, J. Pérez-Ramírez, Highly selective Lewis acid sites in desilicated MFI zeolites for dihydroxyacetone isomerization to lactic acid, ChemSusChem. 6 (2013) 831-839.

[48] A. Onda, T. Ochi, K. Kajiyoshi, K. Yanagisawa, Lactic acid production from glucose over activated hydrotalcites as solid base catalysts in water, Catal. Commun. 9 (2008) 10501053.

[49] Z. Liu, W. Li, C. Pan, P. Chen, H. Lou, X. Zheng, Conversion of biomass-derived carbohydrates to methyl lactate using solid base catalysts, Catal. Commun. 15 (2011) $82-$ 87. 
[50] S. Brand, F. Hardi, J. Kim, D.J. Suh, Effect of heating rate on biomass liquefaction: Differences between subcritical water and supercritical ethanol, Energy. 68 (2014) 420427.

[51] P. Lalanne, J.M. Andanson, J.-C. Soetens, T. Tassaing, Y. Danten, M. Besnard, Hydrogen bonding in supercritical ethanol assessed by infrared and raman spectroscopies, J. Phys. Chem. A. 108 (2004) 3902-3909.

[52] J. Peng, P. Chen, H. Lou, X. Zheng, Upgrading of Bio-oil over aluminum silicate in supercritical ethanol, Energy \& Fuels. 22 (2008) 3489-3492.

[53] B. Jin, P. Duan, Y. Xu, B. Wang, F. Wang, L. Zhang, Lewis acid-catalyzed in situ transesterification/esterification of microalgae in supercritical ethanol, Bioresour. Technol. 162 (2014) 341-349.

[54] S. Brand, J. Kim, Liquefaction of major lignocellulosic biomass constituents in supercritical ethanol, Energy. 80 (2015) 64-74.

[55] W. Chen, Z. Luo, C. Yu, G. Li, Y. Yang, H. Zhang, Upgrading of bio-oil in supercritical ethanol: Catalysts screening, solvent recovery and catalyst stability study, J. Supercrit. Fluids. 95 (2014) 387-393.

[56] C. Tang, H. Tao, X. Zhan, X. Xie, Mechanism of esters formation during cellulose liquefaction in sub- and supercritical ethanol, BioResources. 9 (2014) 4946-4957.

[57] X. Huang, T.I. Korányi, M.D. Boot, E.J.M. Hensen, Catalytic depolymerization of lignin in supercritical ethanol, ChemSusChem. 7 (2014) 2276-2288.

[58] S. Mukai, T. Koyama, K. Tsujii, S. Deguchi, Anomalous long-range repulsion between silica surfaces induced by density inhomogeneities in supercritical ethanol, Soft Matter. 10 (2014) 6645-6650.

[59] Q. Zhang, Y. Xu, Y. Li, T. Wang, Q. Zhang, L. Ma, et al., Investigation on the esterification by using supercritical ethanol for bio-oil upgrading, Appl. Energy. (2015) In Press.

[60] S. Brand, R.F. Susanti, S.K. Kim, H.S. Lee, J. Kim, B.I. Sang, Supercritical ethanol as an enhanced medium for lignocellulosic biomass liquefaction: Influence of physical process parameters, Energy. 59 (2013) 173-182.

[61] N.P. Vasilakos, D.M. Austgen, Hydrogen-donor solvents in biomass liquefaction, Ind. Eng. Chem. Process Des. Dev. 24 (1985) 304-311.

[62] T. Nakagawa, H. Ozaki, T. Kamitanaka, H. Takagi, T. Matsuda, T. Kitamura, et al., Reactions of supercritical alcohols with unsaturated hydrocarbons, J. Supercrit. Fluids. 27 (2003) 255-261. 
[63] Z. Yuan, S. Cheng, M. Leitch, C. (Charles) Xu, Hydrolytic degradation of alkaline lignin in hot-compressed water and ethanol, Bioresour. Technol. 101 (2010) 9308-9313.

[64] T. Ebukuro, A. Takami, Y. Oshima, S. Koda, Raman spectroscopic studies on hydrogen bonding in methanol and methanol/water mixtures under high temperature and pressure, J. Supercrit. Fluids. 15 (1999) 73-78.

[65] A.R. Bazaev, I.M. Abdulagatov, E.A. Bazaev, A.A. Abdurashidova, A.E. Ramazanova, PVT measurements for pure methanol in the near-critical and supercritical regions, J. Supercrit. Fluids. 41 (2007) 217-226.

[66] D.M. Do, S. Jaenicke, G.K. Chuah, Mesoporous Zr-SBA-15 as a green solid acid catalyst for the Prins reaction, Catal. Sci. Technol. 2 (2012) 1417-1424.

[67] Y. Konishi, M. Okazaki, K. Toriyama, T. Kasai, Nanotube effect on a liquid-phase photoreaction in mesoporous silica, J. Phys. Chem. B. 105 (2001) 9101-9106.

[68] D. Wei, W. Te Chueh, G.L. Haller, Catalytic behavior of vanadium substituted mesoporous molecular sieves, Catal. Today. 51 (1999) 501-511.

[69] X. Hu, M.L. Foo, G.K. Chuah, S. Jaenicke, Pore size engineering on MCM-41: selectivity tuning of heterogenized $\mathrm{AlCl} 3$ for the synthesis of linear alkyl benzenes, J. Catal. 195 (2000) 412-415.

[70] C. Pirez, J. Caderon, J. Dacquin, A.F. Lee, K. Wilson, Tunable KIT-6 mesoporous sulfonic acid catalysts for fatty acid esterification, ACS Catal. 2 (2012) 1607-1614.

[71] J. Wang, Y. Masui, M. Onaka, Conversion of triose sugars with alcohols to alkyl lactates catalyzed by Brønsted acid tin ion-exchanged montmorillonite, Appl. Catal. B Environ. 107 (2011) 135-139.

[72] P.P. Pescarmona, K.P.F. Janssen, C. Delaet, C. Stroobants, K. Houthoofd, A. Philippaerts, et al., Zeolite-catalysed conversion of C3 sugars to alkyl lactates, Green Chem. 12 (2010) 1083-1089.

[73] J.P. Lange, W.D. van de Graaf, R.J. Haan, Conversion of furfuryl alcohol into ethyl levulinate using solid acid catalysts, ChemSusChem. 2 (2009) 437-441.

[74] M. Boronat, A. Corma, M. Renz, Mechanism of the Meerwein-Ponndorf-VerleyOppenauer (MPVO) redox equilibrium on Sn- and Zr-beta zeolite catalysts, J. Phys. Chem. B. 110 (2006) 21168-21174.

[75] A. Corma, M.E. Domine, L. Nemeth, S. Valencia, Al-free Sn-Beta zeolite as a catalyst for the selective reduction of carbonyl compounds (Meerwein-Ponndorf-Verley Reaction), J. Am. Chem. Soc. 124 (2002) 3194-3195. 
[76] A. Corma, M.E. Domine, S. Valencia, Water-resistant solid Lewis acid catalysts: Meerwein-Ponndorf-Verley and oppenauer reactions catalyzed by tin-beta zeolite, J. Catal. 215 (2003) 294-304.

[77] G. Li, E.A. Pidko, E.J.M. Hensen, Synergy between Lewis acid sites and hydroxyl groups for the isomerization of glucose to fructose over Sn-containing zeolites: a theoretical perspective, Catal. Sci. Technol. 4 (2014) 2241-2250. 


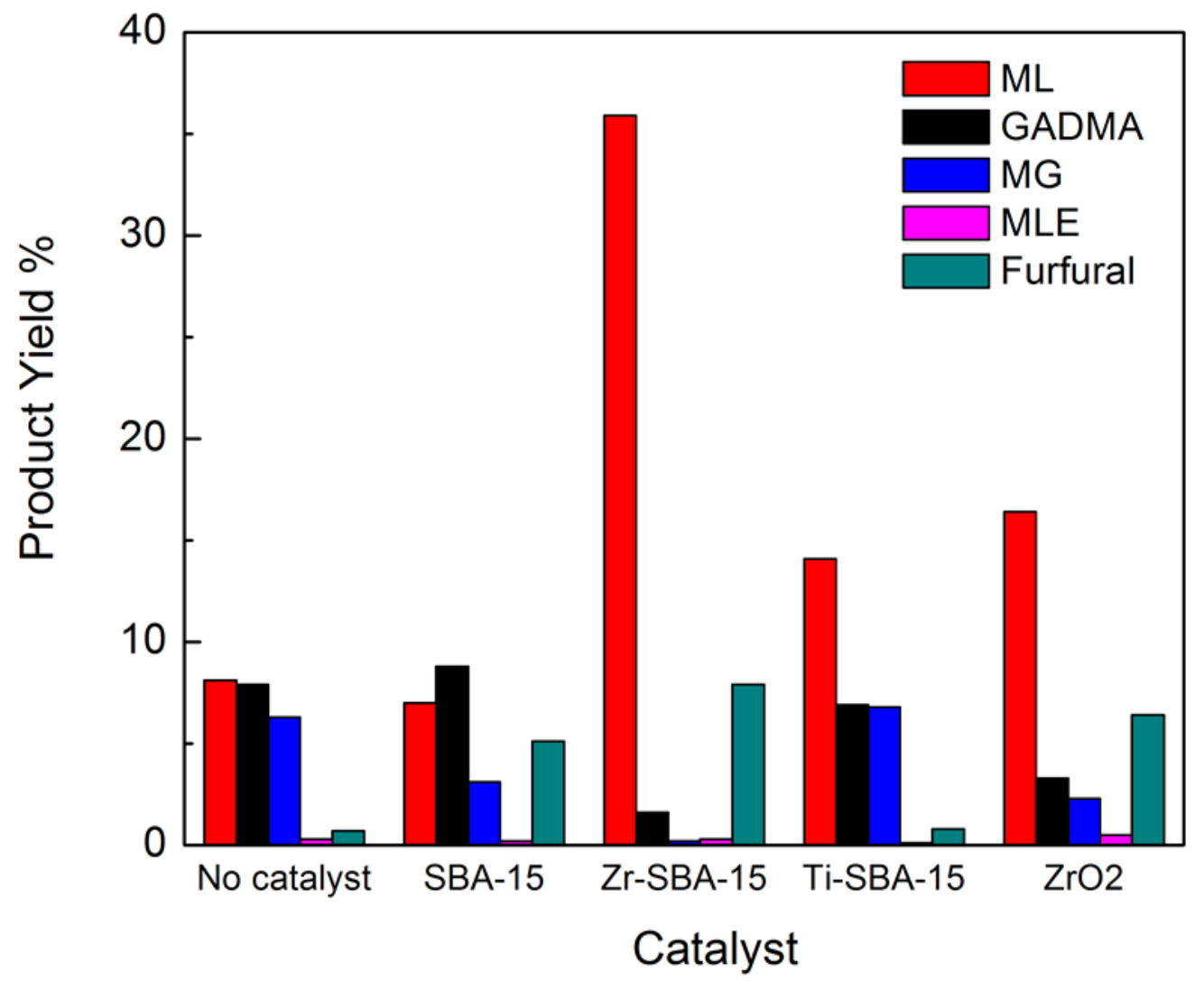

Fig. 1. Comparison of different catalysts towards the conversion of xylose in methanol. Reaction conditions: $240^{\circ} \mathrm{C}, 1 \mathrm{~h}, 400 \mathrm{psi} \mathrm{N}_{2}, 0.2 \mathrm{~g}$ xylose loading, $0.1 \mathrm{~g}$ catalyst.

ML: Methyl lactate, GADMA: Glycolaldehyde dimethyl acetal, MG: Methyl glycolate, MLE: Methyl levulinate. 


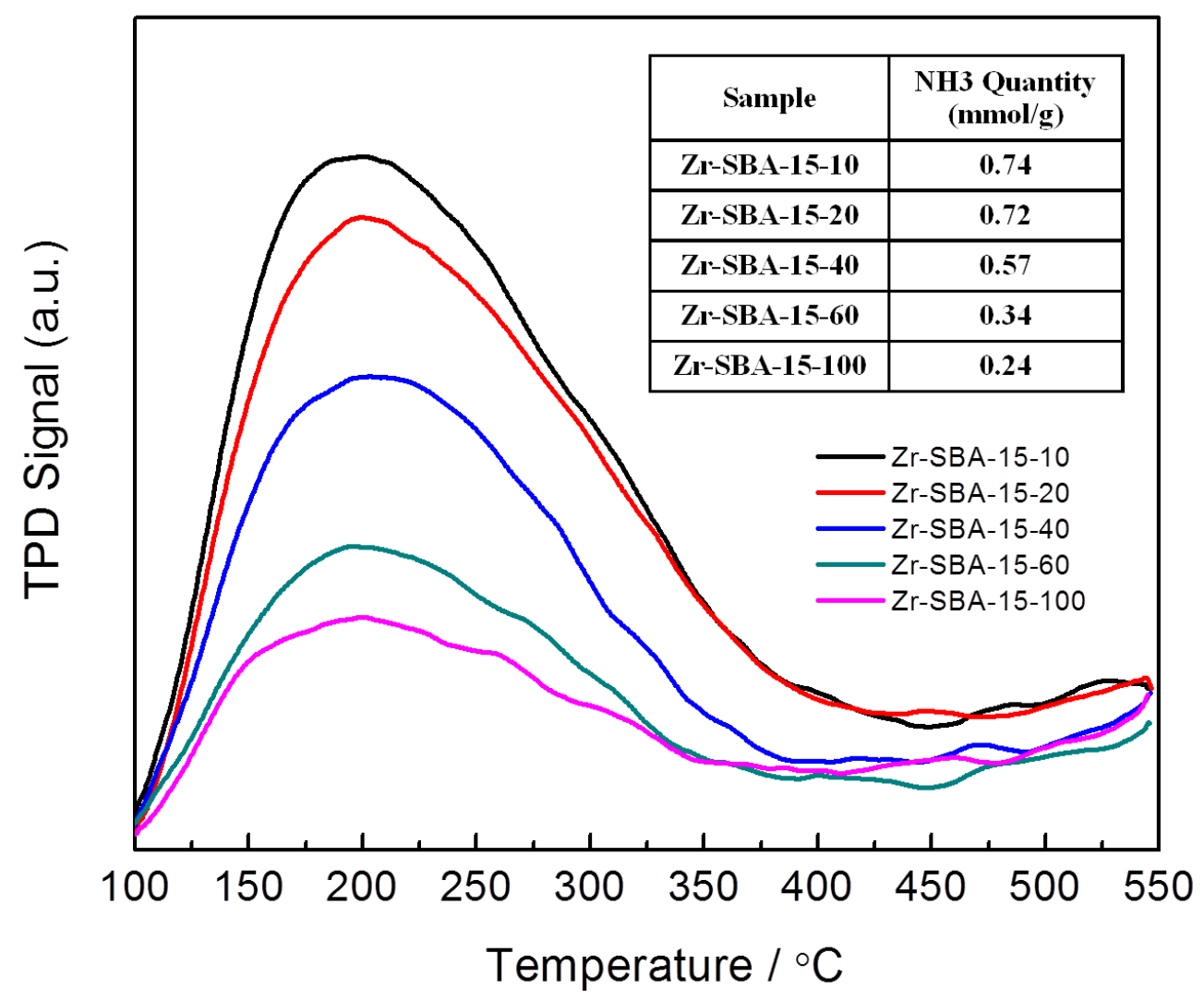

Fig. 2. Temperature-programmed desorption of ammonia ( $\left.\mathrm{NH}_{3}-\mathrm{TPD}\right)$ for $\mathrm{Zr}-\mathrm{SBA}-15$ materials with different $\mathrm{Si} / \mathrm{Zr}$ molar ratios. All materials were synthesized at the hydrothermal temperature of $100^{\circ} \mathrm{C}$. 


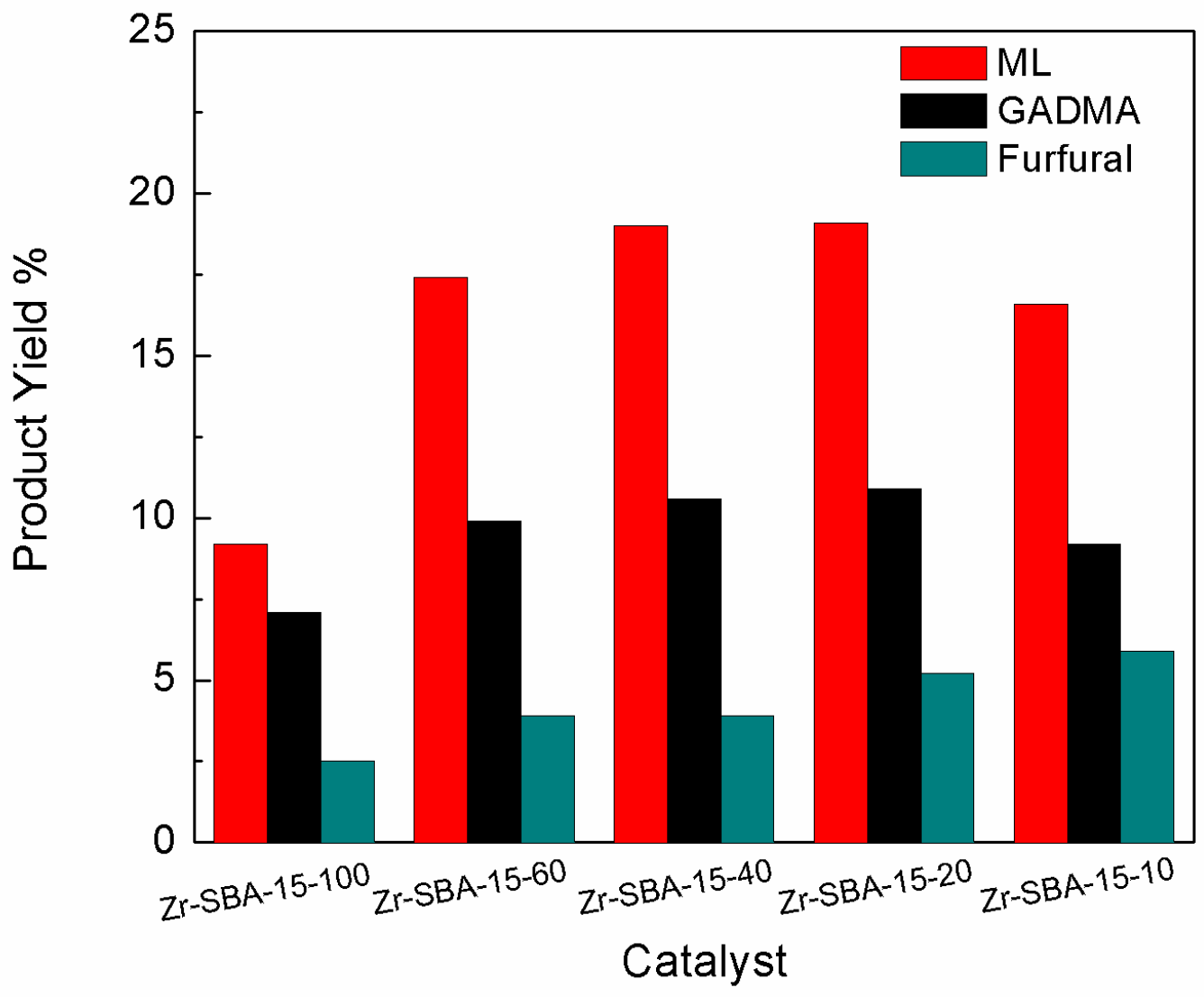

Fig. 3. Comparison of different $\mathrm{Zr}^{4+}$ ion loading on SBA-15 towards the conversion of xylose in methanol. Reaction conditions: $180^{\circ} \mathrm{C}, 60 \mathrm{~min}, 400 \mathrm{psi}$ initial $\mathrm{N}_{2}$ pressure, $0.2 \mathrm{~g}$ xylose, and $0.1 \mathrm{~g}$ catalyst. ML: Methyl lactate, GADMA: Glycolaldehyde dimethylacetal. 


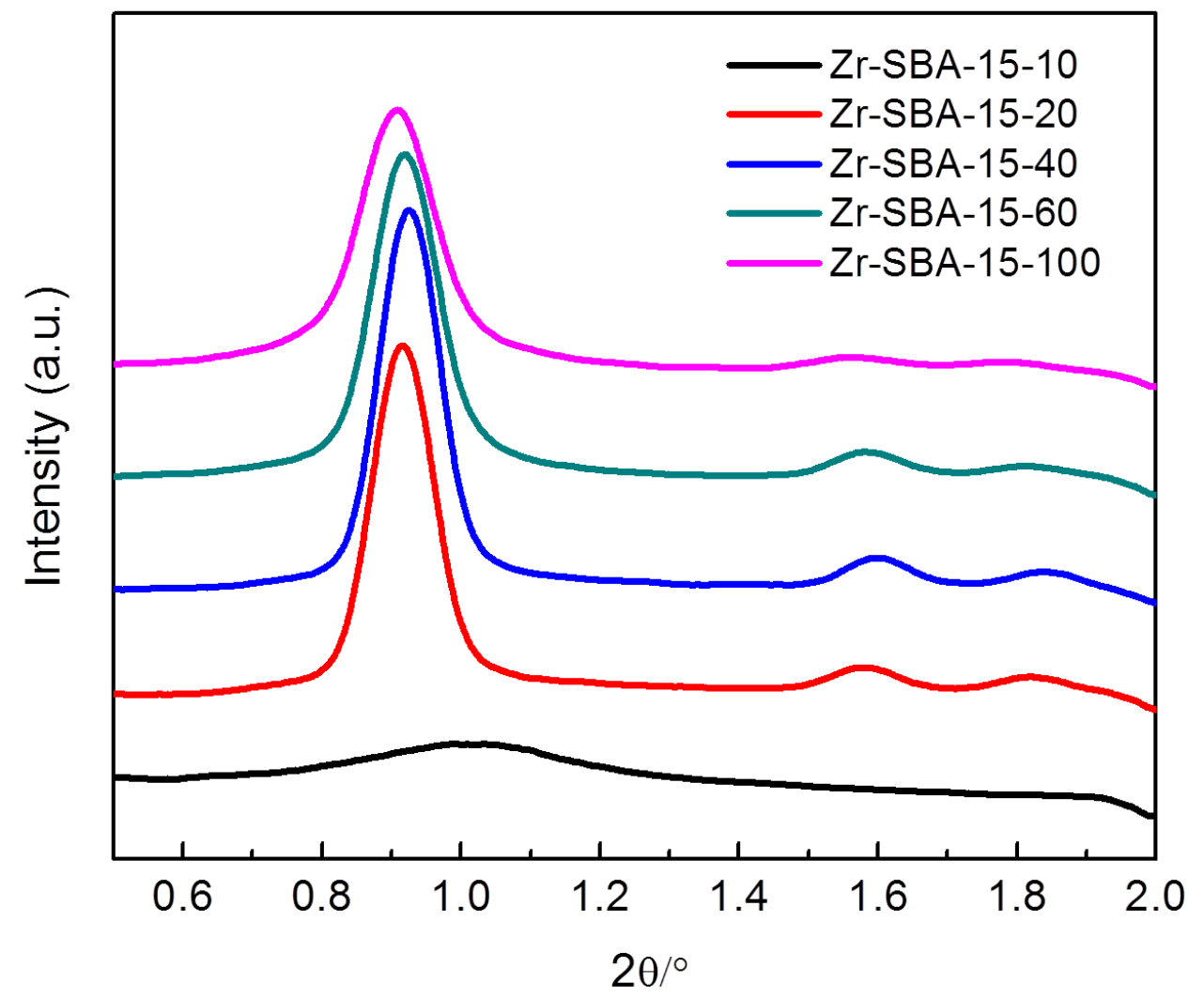

Fig. 4. Small-angle $X$-ray scattering patterns of Zr-SBA-15 materials with different Si/Zr molar ratios. All materials were synthesized at the hydrothermal temperature of $100^{\circ} \mathrm{C}$. 


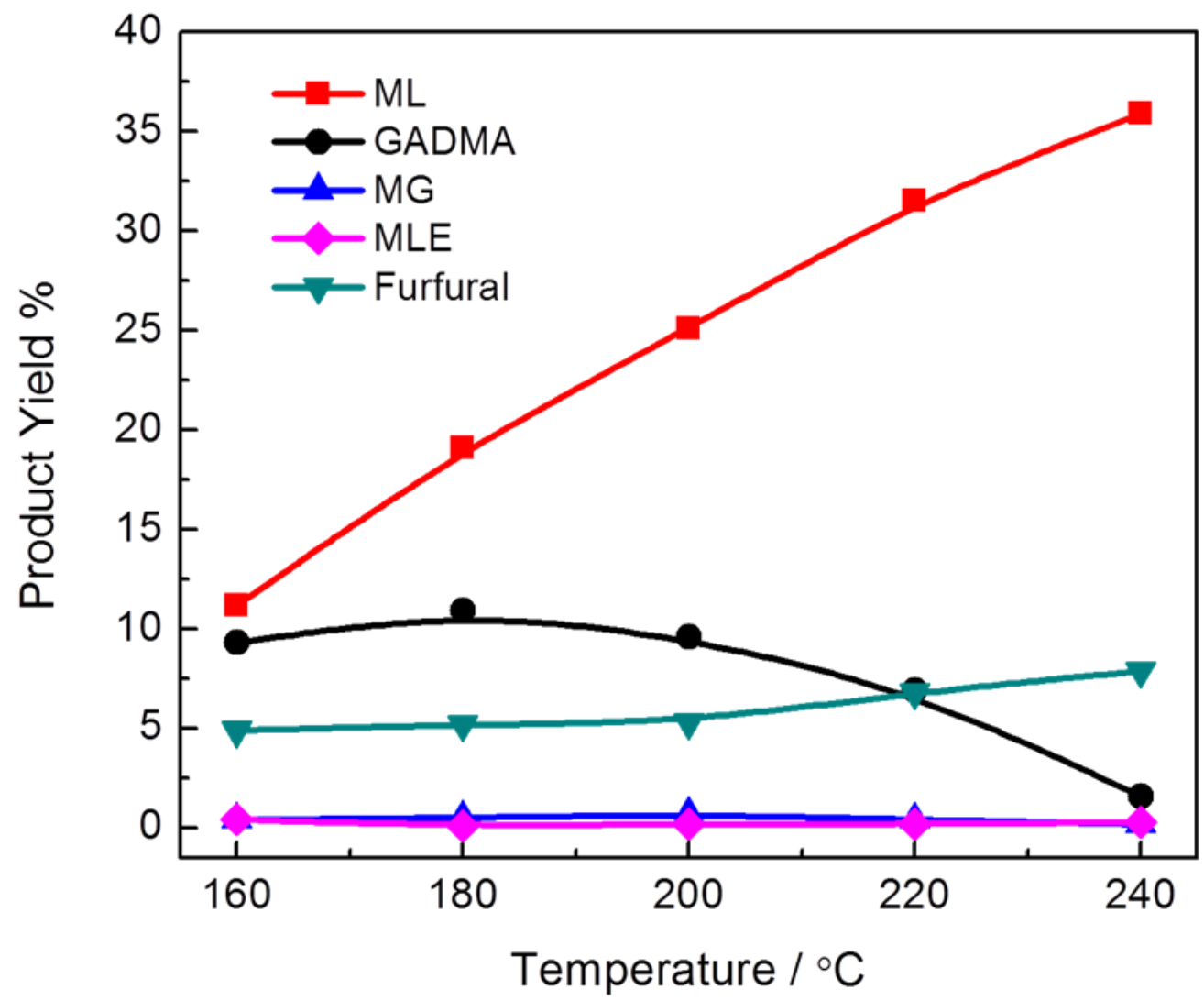

Fig. 5. Effect of temperature on the yields liquids-phase products of xylose conversion with the Zr-SBA15 catalyst in methanol. Reaction conditions: (a) 1 hour, 400 psi initial $\mathrm{N}_{2}$ pressure, $0.2 \mathrm{~g}$ xylose, and 0.1 g catalyst; (b) 10 hours, 400psi N2, $0.2 \mathrm{~g}$ xylose, and $0.1 \mathrm{~g}$ catalyst. ML: Methyl lactate, GADMA: Glycolaldehyde dimethylacetal,

MG: Methyl glycolate, MLE: Methly levulinate. 


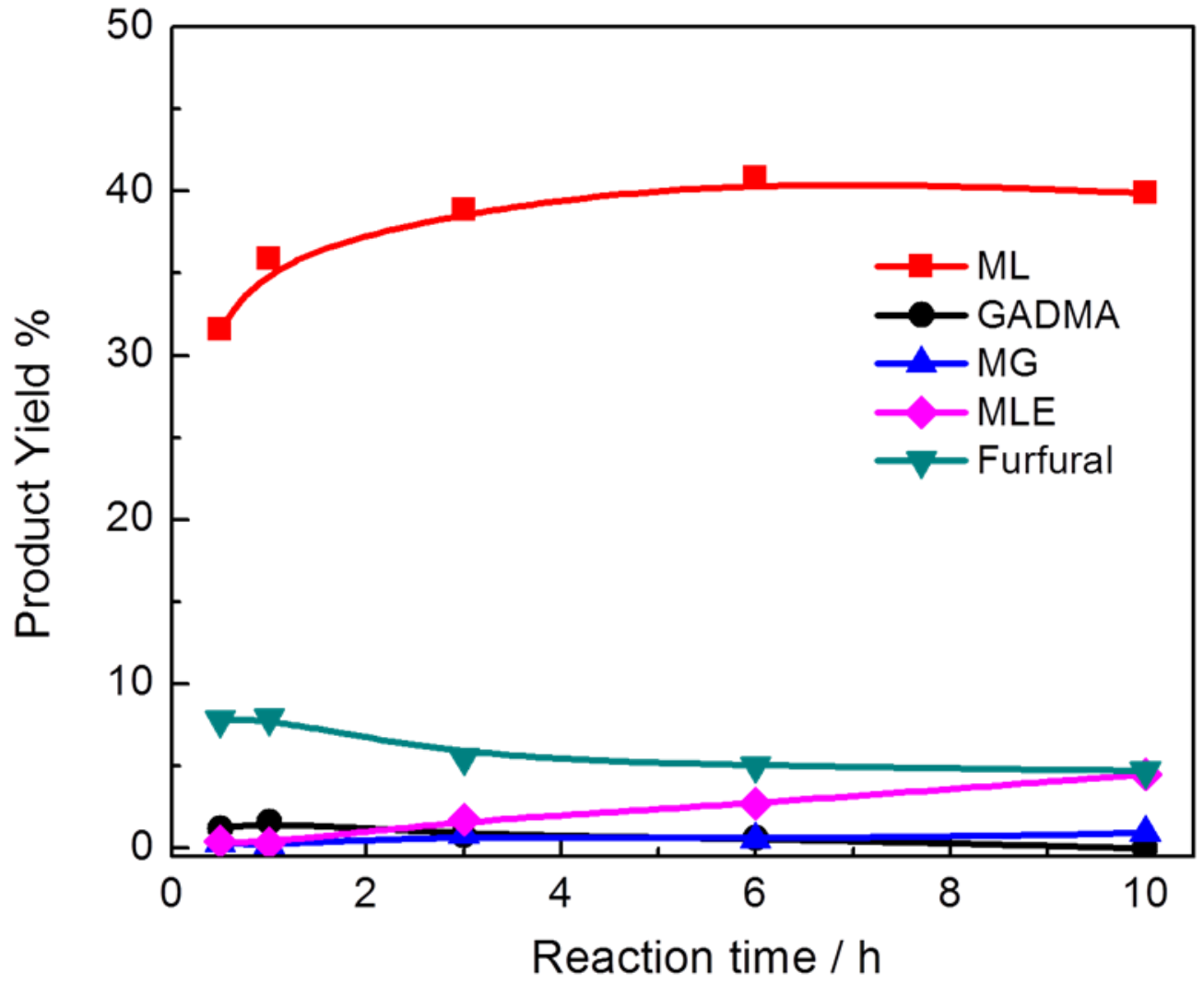

Fig. 6. Effect of reaction time on the yields liquids-phase products of xylose conversion with the Zr-SBA15 catalyst in methanol. Reaction conditions: $240^{\circ} \mathrm{C}, 400$ psi initial $\mathrm{N}_{2}$ pressure, $0.2 \mathrm{~g}$ xylose, and $0.1 \mathrm{~g}$ catalyst. ML: Methyl lactate, GADMA: Glycolaldehyde dimethylacetal, MG: Methyl glycolate, MLE: Methly levulinate. 


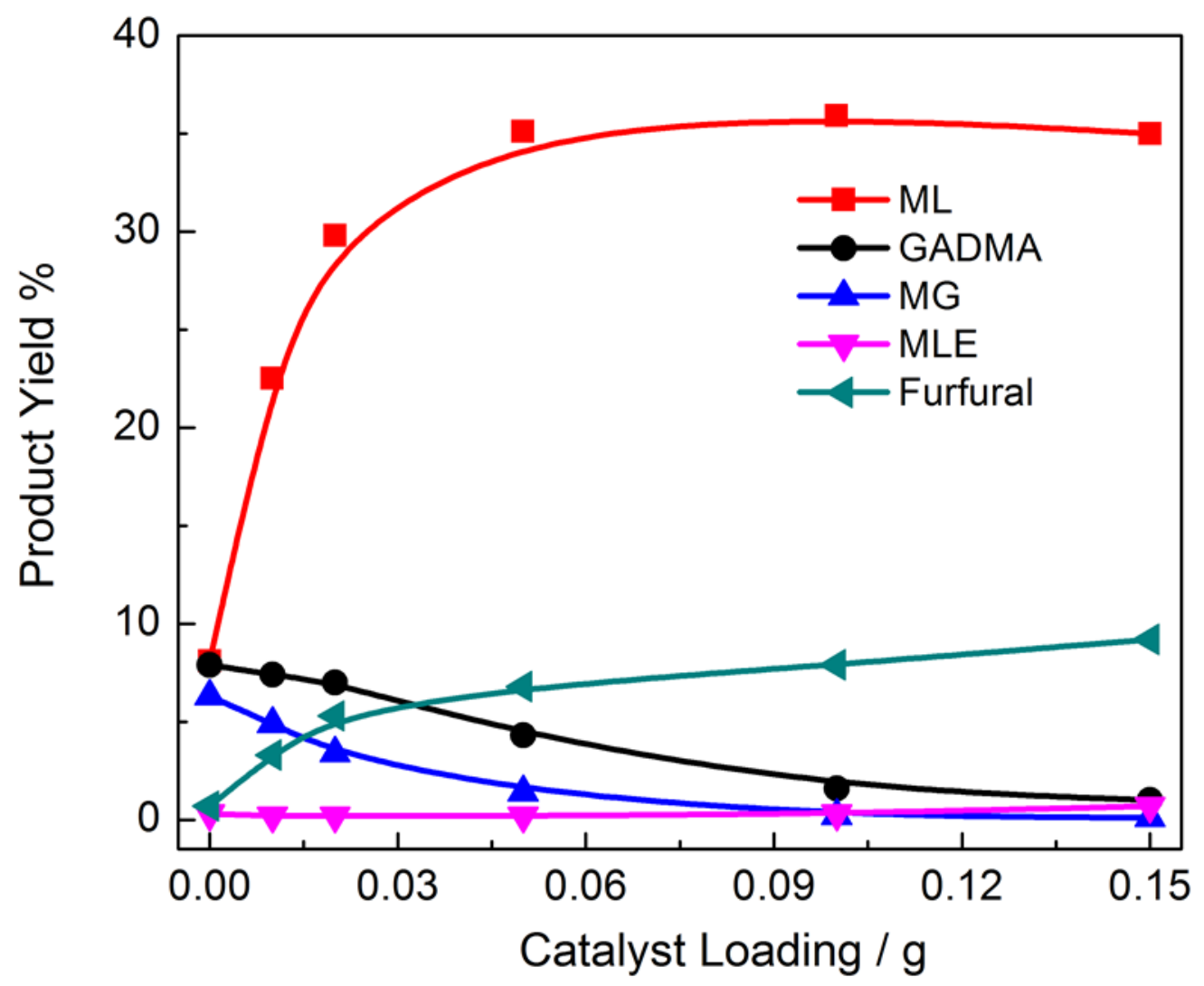

Fig. 7. Effect of catalyst loading on the yields of liquids-phase products of xylose conversion with the $\mathrm{Zr}$ SBA-15 catalyst in methanol. Reaction conditions: $240^{\circ} \mathrm{C}, 1$ hour, $400 \mathrm{psi}$ initial $\mathrm{N}_{2}$ pressure, $0.2 \mathrm{~g}$ xylose. ML: Methyl lactate, GADMA: Glycolaldehyde dimethylacetal, MG: Methyl glycolate, MLE: Methly levulinate. 


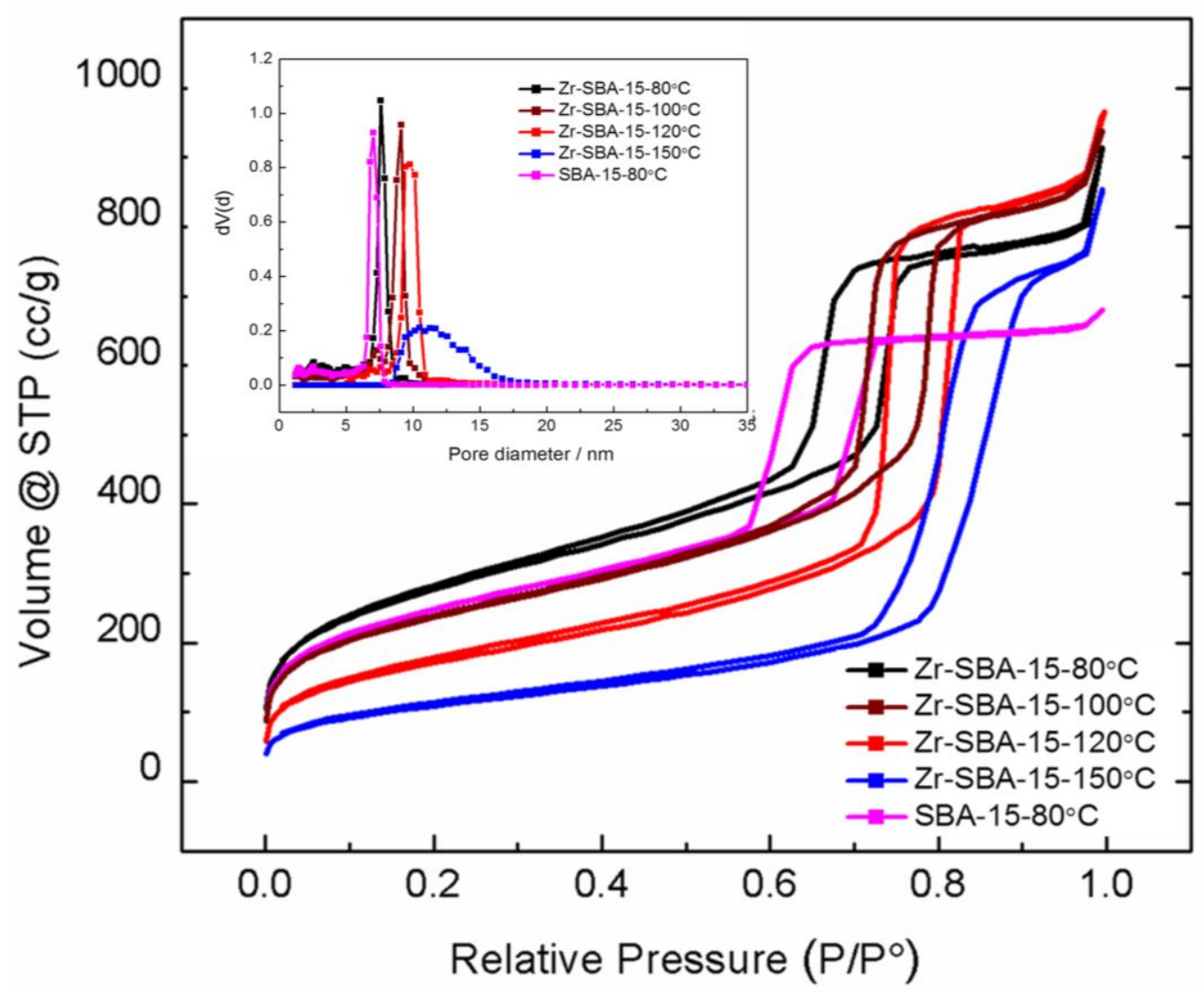

Fig. 8. Nitrogen adsorption-desorption isotherms of the Zr-SBA-15 materials; inset is the pore size distribution determined by NLDFT model for adsorption branch for $\mathrm{N}_{2}$ on silica at $77 \mathrm{~K}$ (cylindrical pore model). 


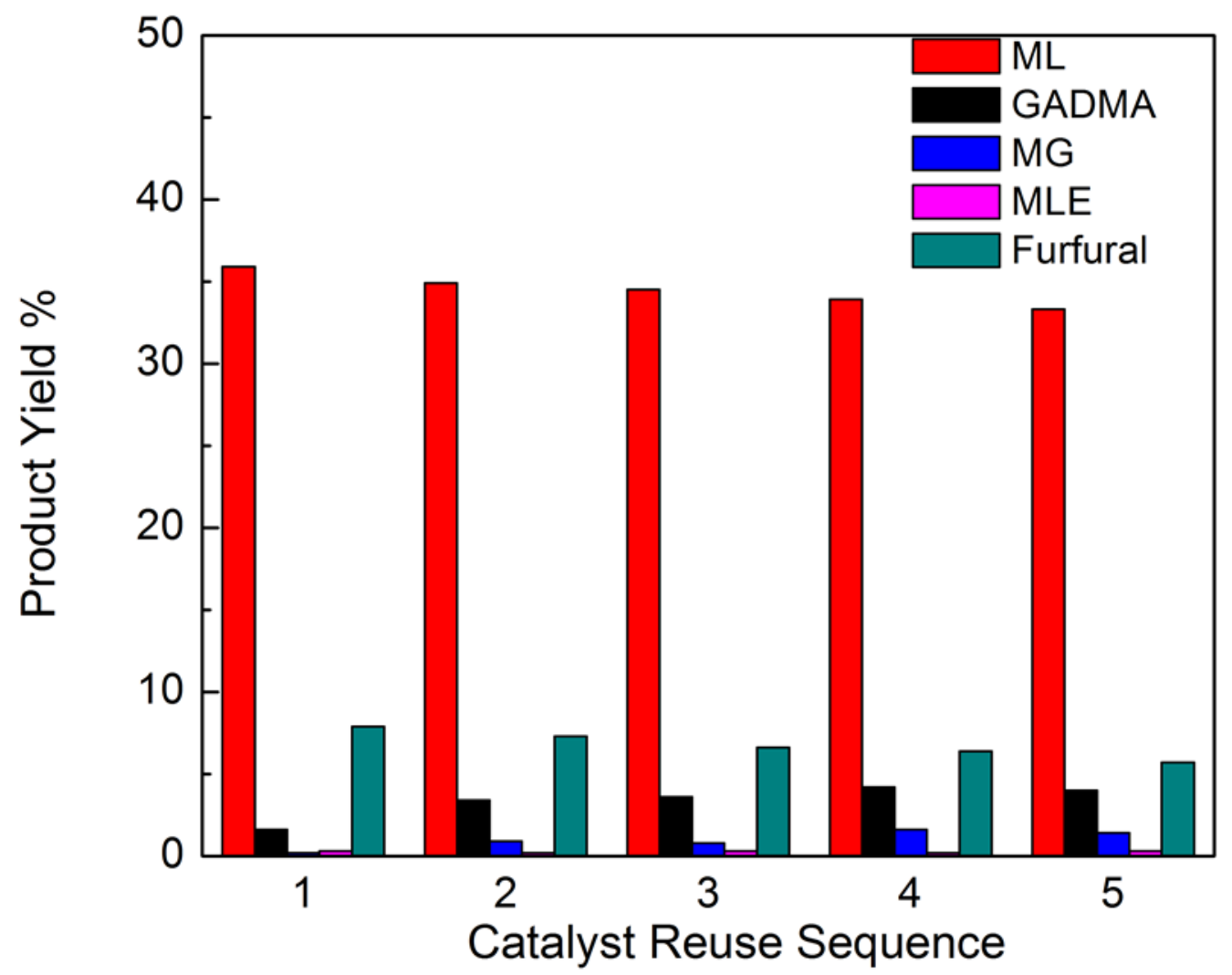

Fig. 9. Re-use of the Zr-SBA-15 catalyst in the conversion of xylose. The spent catalysts were not regenerated. Reaction conditions: $240^{\circ} \mathrm{C}, 1$ hour, 400 psi initial $\mathrm{N}_{2}$ pressure, $0.2 \mathrm{~g}$ xylose, $0.1 \mathrm{~g}$ catalyst. ML: Methyl lactate, GADMA: Glycolaldehyde dimethylacetal, MG: Methyl glycolate, MLE: Methly levulinate. 


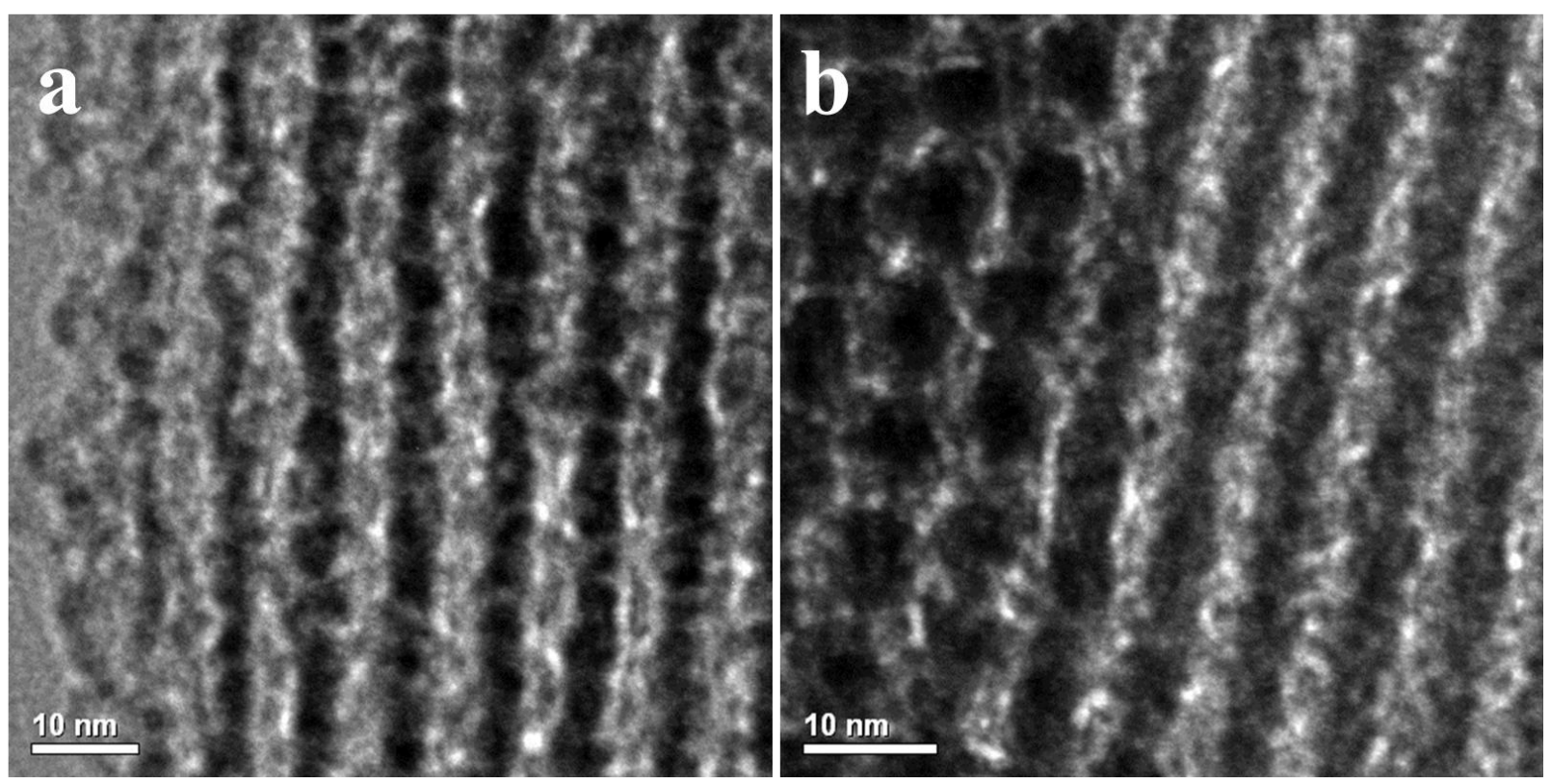

Fig. 10. High-resolution transmission electron microscopy (HRTEM) image of Zr-SBA-15: (a) fresh sample; (b) spent sample after five consecutive runs. 
Table 1. Comparison of the effect of different pore sizes of Zr-SBA-15 on the catalytic conversion of xylose to methyl lactate in methanol solvent.

\begin{tabular}{cccccccccc}
\hline \multirow{2}{*}{ Entry } & \multirow{2}{*}{ Feedstock } & \multirow{2}{*}{ Catalyst } & \multirow{2}{*}{ Conversion } & \multirow{2}{*}{ Solid residue } & \multicolumn{4}{c}{ Carbon Yield/\% } \\
\cline { 6 - 9 } & & & & ML & GDA & MG & MLE & Furfural \\
\hline 1 & Xylose & $\mathrm{Zr}-\mathrm{SBA}-15-80^{\circ} \mathrm{C}$ & $>99 \%$ & $17.4 \%$ & 30.9 & 1.0 & 0.1 & 0.6 & 9.2 \\
2 & Xylose & $\mathrm{Zr}-\mathrm{SBA}-15-100^{\circ} \mathrm{C}$ & $>99 \%$ & $10.8 \%$ & 35.9 & 1.6 & 0.2 & 0.3 & 7.9 \\
3 & Xylose & $\mathrm{Zr}-\mathrm{SBA}-15-120^{\circ} \mathrm{C}$ & $>99 \%$ & $9.2 \%$ & 34.1 & 3.0 & 1.0 & 0.2 & 7.3 \\
4 & Xylose & $\mathrm{Zr}-\mathrm{SBA}-15-150^{\circ} \mathrm{C}$ & $>99 \%$ & $6.9 \%$ & 34.3 & 8.7 & 1.2 & 0.2 & 6.4 \\
\hline
\end{tabular}

Reaction conditions: $240{ }^{\circ} \mathrm{C}, 1 \mathrm{~h}, 400 \mathrm{psi} \mathrm{N}_{2}$ pressure, $0.2 \mathrm{~g}$ feedstock loading, and $0.1 \mathrm{~g}$ catalyst. ML: Methyl lactate, GADMA: Glycolaldehyde dimethylacetal, MG: Methyl glycolate, MLE: Methly levulinate. 
Table 2. The physicochemical properties of Zr-SBA-15 silicates.

\begin{tabular}{|c|c|c|c|c|}
\hline Catalyst $^{\mathrm{a}}$ & $\begin{array}{l}\text { BET Surface } \\
\text { area }^{b} / \mathrm{m}^{2} \mathrm{~g}^{-1}\end{array}$ & $\begin{array}{c}\text { Pore volume } \\
\text { determined by } \\
\text { NLDFT model } \\
\quad / \mathrm{cm}^{\mathrm{c}} \mathrm{g}^{-1}\end{array}$ & $\begin{array}{c}\text { Pore size } \\
\text { determined by } \\
\text { NLDFT model }^{\mathrm{c}} / \\
\mathrm{nm}\end{array}$ & $\begin{array}{c}\text { Acid strength } \\
\mathrm{NH}_{3} \text { Quantity }(\mathrm{mmol} / \mathrm{g})\end{array}$ \\
\hline SBA- $15-100^{\circ} \mathrm{C}$ & 876 & 0.998 & 7.0 & 0.02 \\
\hline $\mathrm{Zr}-\mathrm{SBA}-15-80^{\circ} \mathrm{C}$ & 988 & 1.275 & 7.6 & 0.65 \\
\hline $\mathrm{Zr}-\mathrm{SBA}-15-100^{\circ} \mathrm{C}$ & 841 & 1.357 & 9.1 & 0.72 \\
\hline $\mathrm{Zr}-\mathrm{SBA}-15-120^{\circ} \mathrm{C}$ & 618 & 1.384 & 9.8 & 0.69 \\
\hline $\mathrm{Zr}-\mathrm{SBA}-15-150^{\circ} \mathrm{C}$ & 393 & 1.215 & 10.6 & 0.51 \\
\hline
\end{tabular}

${ }^{\mathrm{a}} \mathrm{The}$ mole ratio of $\mathrm{Si} / \mathrm{Zr}$ is 20 for the catalysts.

${ }^{\mathrm{b}}$ BET surface area calculated using the BET (Bruanauer-Emmett-Teller) equation at relative pressures between 0.05 and 0.25 using the adsorption branch.

${ }^{\mathrm{c}}$ Cylindrical pore model applied for $\mathrm{N}_{2}$ adsorption on silica at $77 \mathrm{~K}$ for the adsorption branch. 
Table 3. Comparison of the conversion of different carbohydrate feedstocks with the Zr-SBA-15 catalyst in methanol and/or water solvents.

\begin{tabular}{|c|c|c|c|c|c|c|c|c|c|c|}
\hline \multirow{2}{*}{ Entry } & \multirow{2}{*}{ Feedstock } & \multirow{2}{*}{ Catalyst } & \multirow{2}{*}{$\begin{array}{c}\text { Time/ } \\
\mathbf{h}\end{array}$} & \multirow{2}{*}{ Solvent } & \multicolumn{6}{|c|}{ Carbon Yield/\% } \\
\hline & & & & & ML & GADMA & MG & MLE & Furfural & HMF \\
\hline 1 & Xylose & 1 & $1 \mathrm{~h}$ & Methanol & 8.1 & 7.9 & 6.3 & 1 & 1 & 1 \\
\hline 2 & Xylose & Zr-SBA-15 & $1 \mathrm{~h}$ & Methanol & 35.9 & 1.6 & 0.2 & l & l & l \\
\hline 3 & Xylose & 1 & $1 \mathrm{~h}$ & Water & 3.0(Lactic acid) & I & I & I & 21.2 & I \\
\hline 4 & Xylose & Zr-SBA-15 & $1 \mathrm{~h}$ & Water & 5.9(Lactic acid) & / & I & I & 42.3 & I \\
\hline 4 & Glyceraldehyde & l & $1 \mathrm{~h}$ & Methanol & 19.9 & 2.3 & 2.9 & l & l & l \\
\hline 5 & Glyceraldehyde & Zr-SBA-15 & $1 \mathrm{~h}$ & Methanol & 78.8 & 2.5 & 0.8 & / & / & l \\
\hline 6 & Dihydroxy acetone & l & $1 \mathrm{~h}$ & Methanol & 29.5 & 1.9 & 3.3 & l & l & l \\
\hline 7 & Dihydroxy acetone & Zr-SBA-15 & $1 \mathrm{~h}$ & Methanol & 84.5 & 1.9 & 0.9 & l & l & l \\
\hline 8 & Pyruvaldehyde & l & $1 \mathrm{~h}$ & Methanol & 64.5 & 0.7 & 0.2 & l & l & l \\
\hline 9 & Pyruvaldehyde & Zr-SBA-15 & $1 \mathrm{~h}$ & Methanol & 98.7 & 0.8 & 0.2 & I & l & l \\
\hline 10 & Glycoaldehyde & 1 & $1 \mathrm{~h}$ & Methanol & 3.9 & 32.6 & 0.7 & I & I & I \\
\hline 11 & Glycoaldehyde & Zr-SBA-15 & $1 \mathrm{~h}$ & Methanol & 61.3 & 8.4 & 0.6 & l & l & l \\
\hline 12 & GADMA & Zr-SBA-15 & $1 \mathrm{~h}$ & Methanol & 24.0 & I & 0.2 & I & I & I \\
\hline 13 & Xylose & Zr-SBA-15 & $6 \mathrm{~h}$ & Methanol & 40.8 & 0.6 & 0.5 & 2.7 & 3.2 & l \\
\hline 14 & Glucose & Zr-SBA-15 & $6 \mathrm{~h}$ & Methanol & 37.3 & 0.6 & 1.0 & 1.3 & 0.9 & 0.2 \\
\hline 15 & Sucrose & Zr-SBA-15 & $6 \mathrm{~h}$ & Methanol & 39.5 & 0.4 & 0.3 & 2.5 & 1.6 & 2.2 \\
\hline 16 & Fructose & Zr-SBA-15 & $6 \mathrm{~h}$ & Methanol & 44.1 & 0.7 & 0.6 & 3.1 & 1.7 & 1.7 \\
\hline 17 & Glactose & Zr-SBA-15 & $6 \mathrm{~h}$ & Methanol & 14.8 & 0.8 & 0.1 & 7.2 & 0.9 & 2.1 \\
\hline 18 & Mannose & Zr-SBA-15 & $6 \mathrm{~h}$ & Methanol & 31.3 & 1.2 & 0.3 & 8.9 & 1.3 & 1.6 \\
\hline 19 & Arabinose & Zr-SBA-15 & $6 \mathrm{~h}$ & Methanol & 33.4 & 1.3 & 0.5 & 5.4 & 3.7 & 0.1 \\
\hline 20 & Cellobiose & Zr-SBA-15 & $10 \mathrm{~h}$ & Methanol & 24.3 & 0.9 & 0.3 & 4.8 & 1.9 & 2.1 \\
\hline 21 & Cellobiose & Zr-SBA-15 & $10 \mathrm{~h}$ & $95 \%$ Methanol & 26.4 & 1.6 & 0.1 & 3.1 & 2.3 & 1.3 \\
\hline 22 & Cellulose & Zr-SBA-15 & $10 \mathrm{~h}$ & Methanol & 16.7 & 0.1 & 0.1 & 0.7 & 0.2 & 0.7 \\
\hline 23 & Cellulose & Zr-SBA-15 & $10 \mathrm{~h}$ & $95 \%$ Methanol & 28.1 & 0.3 & 0.4 & 2.0 & 1.8 & 1.0 \\
\hline 24 & Starch & Zr-SBA-15 & $10 \mathrm{~h}$ & Methanol & 24.1 & 1.4 & 0.1 & 0.9 & 0.1 & 0.2 \\
\hline 25 & Starch & Zr-SBA-15 & $10 \mathrm{~h}$ & 95\% Methanol & 26.8 & 0.7 & 0.2 & 1.1 & 0.6 & 1.5 \\
\hline
\end{tabular}

Reaction conditions: $240^{\circ} \mathrm{C}, 400 \mathrm{psi}$ initial $\mathrm{N}_{2}$ pressure, $0.2 \mathrm{~g}$ biomass substrate, and 0.1g Zr-SBA-15. ML: Methyl lactate, GADMA: Glycolaldehyde dimethyl acetal, MG: Methyl glycolate, MLE: Methly levulinate. 


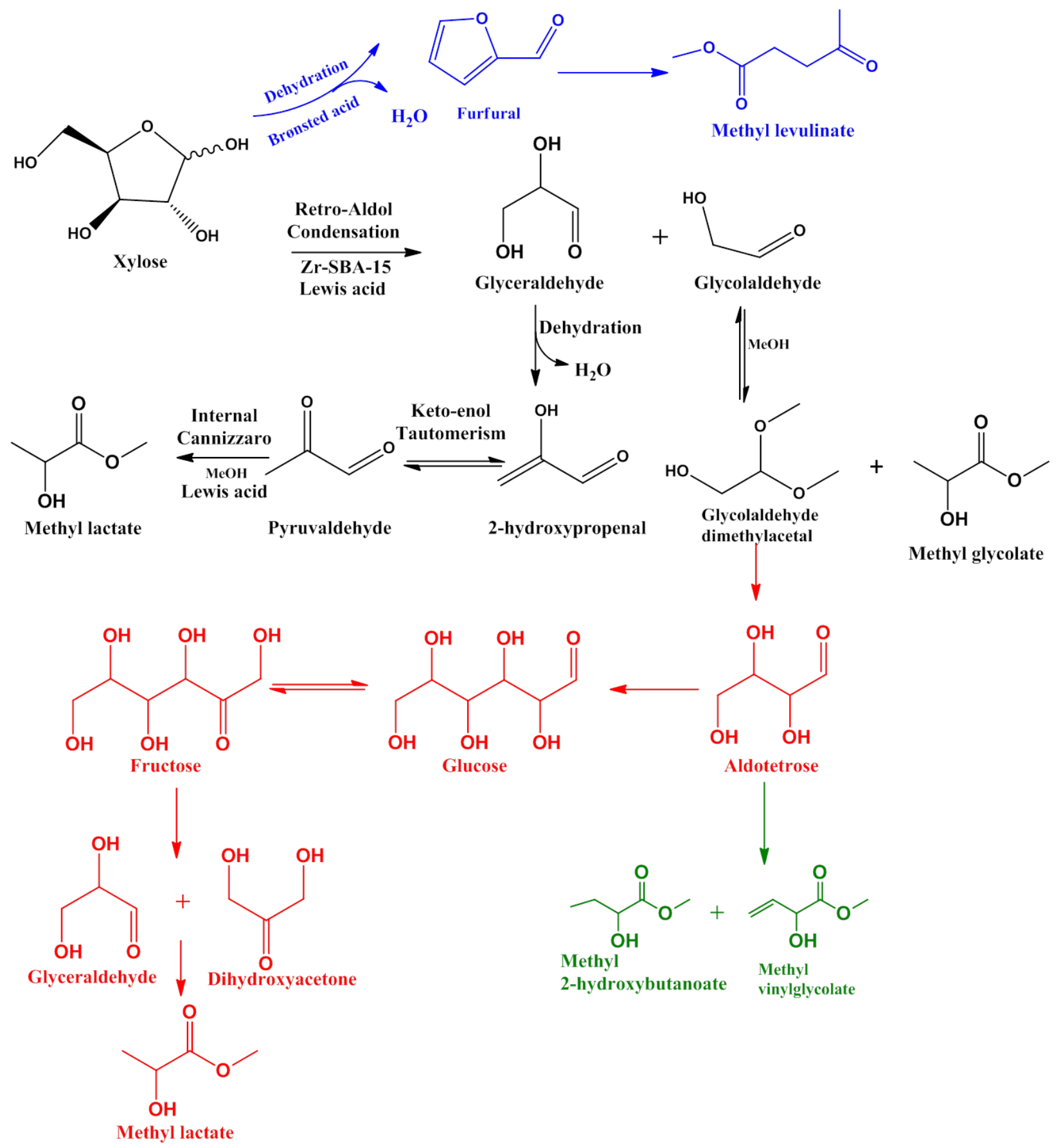

Scheme 1. Proposed reaction mechanism for the conversion of xylose to methyl lactate and other intermediate and final products in methanol solvent with the Zr-SBA-15 catalyst. 
Graphical abstract

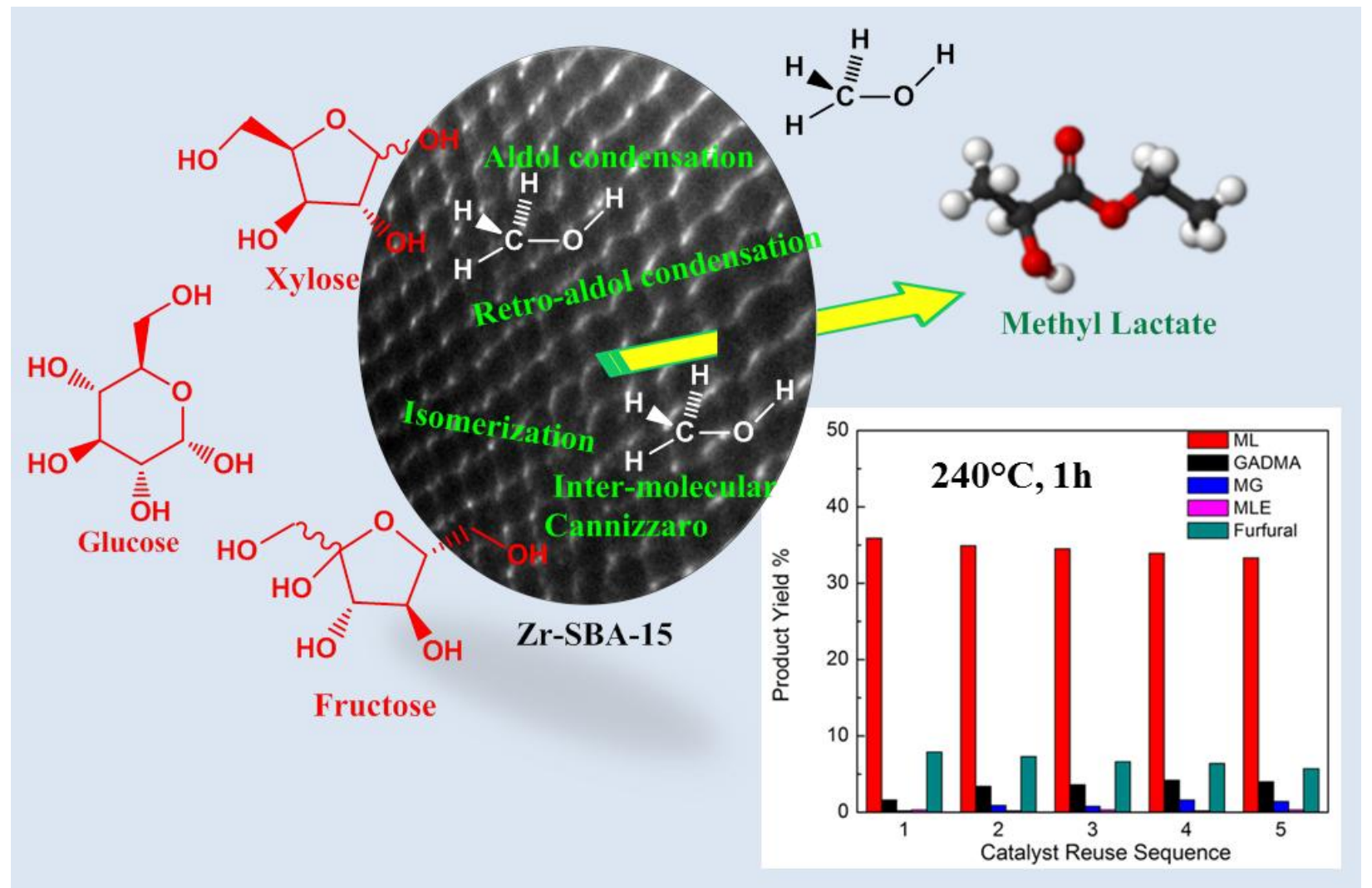

